\title{
E-WASTE AND ITS SUSTAINABLE MANAGEMENT
}

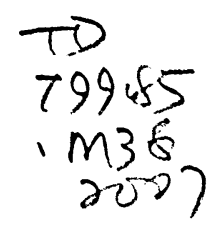

by

Dennis Maslo, Honours BA, University of Guelph, 2000

\begin{abstract}
A Research Project presented to Ryerson University in partial fulfillment of the requirement for the degree of Master of Applied Science

In the program of Environmental Applied Science and Management
\end{abstract}

Toronto, Ontario, Canada, 2007

(C) Dennis Maslo 2007 
UMI Number: EC53572

\section{INFORMATION TO USERS}

The quality of this reproduction is dependent upon the quality of the copy submitted. Broken or indistinct print, colored or poor quality illustrations and photographs, print bleed-through, substandard margins, and improper alignment can adversely affect reproduction.

In the unlikely event that the author did not send a complete manuscript and there are missing pages, these will be noted. Also, if unauthorized copyright material had to be removed, a note will indicate the deletion.

\section{$\mathrm{UMI}^{\circ}$}

UMI Microform EC53572

Copyright 2009 by ProQuest LLC

All rights reserved. This microform edition is protected against unauthorized copying under Title 17, United States Code.

ProQuest LLC

789 East Eisenhower Parkway

P.O. Box 1346

Ann Arbor, MI 48106-1346 
Author's Declaration

I hereby declare that I am the sole author of this project paper.

I authorize Ryerson University to lend this project paper to other institutions or individuals for the purpose of scholarly research.
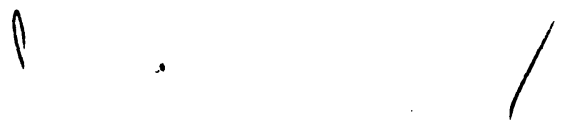

I further authorize Ryerson Unilyersity to reproduce this Project paper by photocopying or by other means, in total or in part, af the request of other institutions or individuals for the purpose of scholarly research.

N

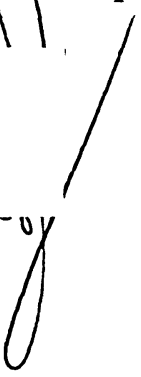




\title{
E-WASTE AND ITS SUSTAINABLE MANAGEMENT
}

Dennis Maslo, 2007

\section{Master of Applied Science}

Environmental Applied Science and Management

Ryerson University

\begin{abstract}
This project paper addresses the problem of e-waste in a local and global context. It examines the origins of the issue, processing methods, and related environmental implications. The worst processing methods, have had devastating impacts on both the physical environment and human organizations. The more widely accepted methods of e-waste processing-recycling-are often exclusive of systematic reuse and do not recognize the initial inputs invested in the equipment. To address the lack of regulation around e-waste disposal and the shortcomings of conventional recycling, a management system for the reuse and refurbishment of discarded IT equipment is proposed that is based on the operations at Computation Ltd., a computer recycling company. This system is recognized as an endof-pipe solution that optimizes various types of waste diversion to include reuse where possible. Future research should focus on green design alternatives and incentives that encourage greater reuse of electronic products.
\end{abstract}


Acknowledgements

I would like to thank the University of Waterloo, and Ryerson University for their efforts in furthering my environmental education.

I would like to send out a special thanks to the staff of Computation Ltd., past and present, for the tangible work they conduct each day in managing electronic wastes.

I would like to thank my family and friends. 


\section{TABLE OF CONTENTS}

LIST OF TABLES $\mathrm{vi}$

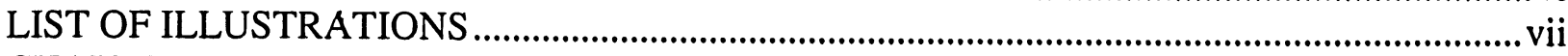

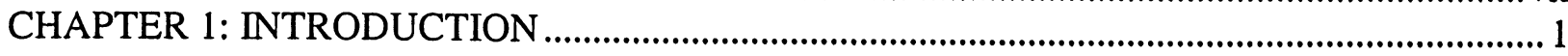

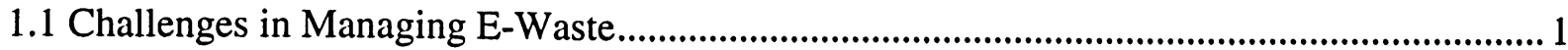

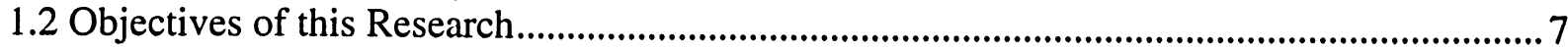

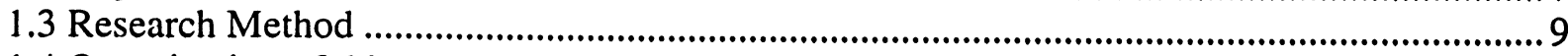

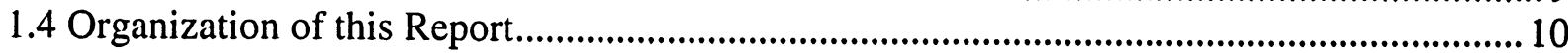

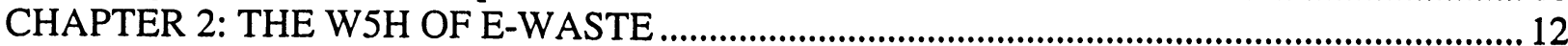

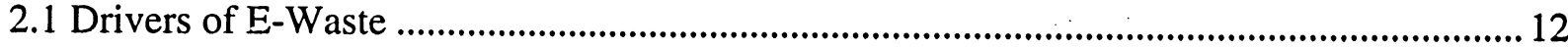

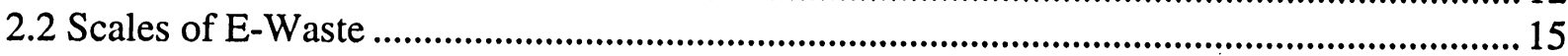

2.3 Production and Consumption of Electronic Products ...................................................... 17

2.4 Driving the Technology Waste Cycle............................................................................ 21

CHAPTER 3: IMPACTS OF AN INSUFFICIENTLY MANAGED PROBLEM .......................28

3.1 Introduction .............................................................................................................228

3.2 Direct or Indirect Disposal via Hazardous Commodity Export to Less-Developed Nations29

3.3 Local Landfilling or Dumping ..................................................................................... 31

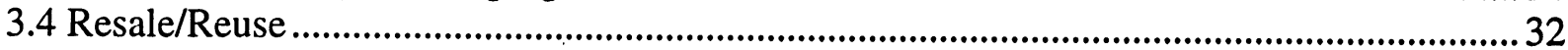

3.5 Semi-Permanent Storage....................................................................................... 34

CHAPTER 4: CURRENT PUBLIC POLICIES ON E-WASTE AND THEIR TRAJECTORIES 36

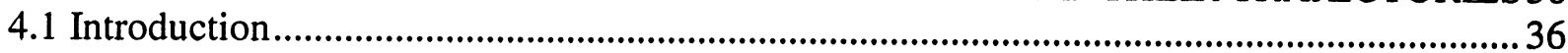

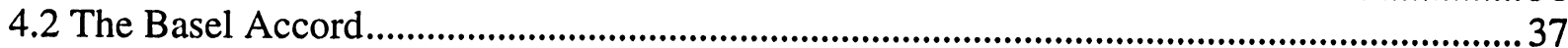

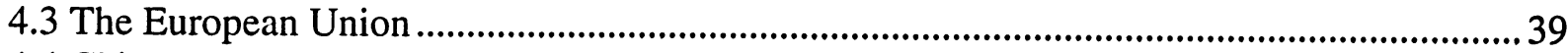

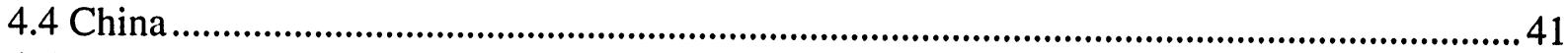

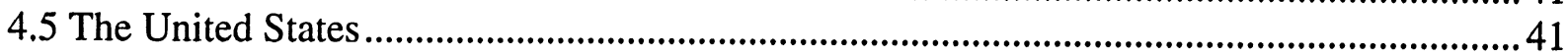

4.6 Ontario, Canada .................................................................................................... 44

CHAPTER 5: PROPOSED SUSTAINABLE E-WASTE MANAGEMENT SYSTEM (SEMS).47

5.1 SEMS: Governing Principles ................................................................................ 48

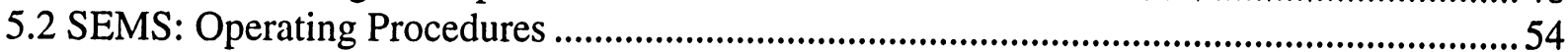

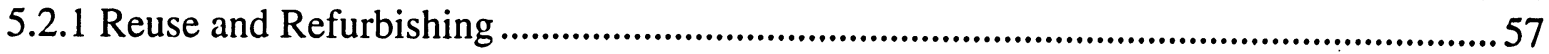

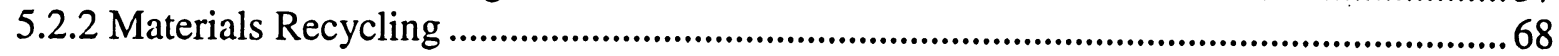

CHAPTER 6: CONCLUSIONS AND FUTURE RESEARCH ............................................... 76

APPENDIX 1 - Signatories to the Basel Accord ......................................................................79

APPENDIX 2 - Ratifiers of the Basel Accord .........................................................................8 80

APPENDIX 3 - eBay Feedback Profile: Computation Services ...................................................8 81 


\section{LIST OF TABLES}

TABLE 1: MATERIAL COMPOSITION OF PCs ................................................................. 18 


\section{LIST OF ILLUSTRATIONS}

ILLUSTRATION 1: INTEL CPUS .23

ILLUSTRATION 2: UNCONTROLLED HANDLING OF E-WASTE 30 


\section{CHAPTER 1: INTRODUCTION}

\subsection{Challenges in Managing E-Waste}

The prevalence and continuing distribution of technological products, both in the developed and in the developing world, requires little introduction. The environmental impact of this ongoing technological boom, however, has been a lagging afterthought and would benefit from increased illumination. As with any product or product category, technological hardware places demands on the environment at each of its life cycle stages, including design, primary resource extraction, manufacturing, marketing, transportation, usage, maintenance, and ultimately, end-of-life disposal. Information technology and other categories of electronics that have reached their endof-life are known as electronic waste, or e-waste. The Economist has recently provided an estimate of annual global e-waste generation that stands at 20 to 50 million tonnes (The Economist, Aug. 25, 2006).

While there are a number of factors that distinguish e-waste from other types of waste, there are also characteristics which suggest similarities with other types of waste. Generally, e-waste can be defined as any to-be-discarded item which requires external electrical energy or battery power to operate, not including other waste categories that include 'white goods' such as refrigerators, air conditioners, and stoves. While this definition of e-waste includes items such as toasters, this report will focus on products with a greater density of electronic circuitry: information technology. Just as important to the utility of this definition as identifying the type of product under consideration, is determining when the definition of e-waste applies. At this early stage in the discussion, it is practical to say that a temporal requirement is met when an owner or administrator deems an electronic product to be ready for disposal. 
Since the introduction of industrial and residential electronics, several economic boom and bust cycles have transpired, numerous product life spans have expired, and multiple generations of product revisions and redesigns have been issued. As a result, the technology industry has risen to occupy the central focus of our economy, despite a humbling market correction. During this time, technology was consumed according to a process followed by many retail products. Initially, the item was purchased at a store, through a catalogue, through a call-centre, or more recently, from an online store. It was then brought to the user's home or place of work. It was opened, plugged in, and it was used. For greater or lesser periods of time, the item was used for leisure or for productive purposes. Eventually, the product either broke, failed to meet the user's needs, was greatly surpassed by new technology, or, also of importance, the unit did not adequately compare to that of the neighbours. This last stage illustrates that disposal-related decisions are driven by social comparison, consumption, new technology, and productivity.

At the juncture of intended disposal, one of three things would have happened. The item would lay idle either where it had been used, or in some place of longer-term storage; it would have been repaired, delaying its seemingly inevitable fate; or it would have been discarded. The first option was merely a holding pen until the item reached the inevitable juncture for all waste: disposal. Depending on the jurisdiction of the user's residence or business and the year of disposal, different types of disposal methods would have been invoked. In the early years, systematic recycling of any material stream may not have been more than a policy idea, so durable goods would have been disposed of via landfilling. For many years, and to this day for many organizations, landfilling would remain the standard solution for items not specifically 
identified for alternative treatments such as the recycling programs that have become commonplace for aluminum cans, glass bottles, and pulp and paper products.

Herein lie the issues of greatest concern. Landfilling can generally be described as an unsustainable practice, if for no other reason than the precise contents of the landfill are largely unregulated, leading to many toxic interactions which can at best be minimized, but not eliminated. In addition, the space and other resources available for landfilling are quite finite. From another, more proactive perspective, the same characteristics that place modern electronics at the height of the technological ladder-namely their relative durability, purity and rarity of raw materials, and intricate design-make it an exceptional waste to dispose of electronics in the 'usual' way. While rare and pure materials are often desirable for one reason or another, some of these materials can be quite toxic. Electronics typically contain varying amounts of heavy and other metals such as lead, cadmium, beryllium, antimony, and mercury (Electronics Product Stewardship Canada, 2006). Whether the toxicity and dispersion of these materials compares poorly or well to other known threats to the environment is not the focus of this report; of greater interest is that a categorically different disposal treatment, one that emphasizes reuse, is in fact beneficial, rather than detrimental.

With the increasing quantity of landfilled e-waste and the increasing annual flow of electronics destined for disposal, greater attention has been given to alternative treatments for the e-waste stream. While different governments certainly recognized the issue at different times, actors in the private sector also had varied levels of recognition. For the most part, however, the private sector was quicker to act, though not necessarily with a sufficient amount of care and planning. 
Thus putative solutions followed the recognition of the e-waste stream. Curiously, for some the e-waste stream was not looked upon as a liability, but rather as a commodity stream. Within this camp there was a further split between those who considered the equipment to be a mass of precious and other types of metals and petrochemically derived compounds in need of re-refining and smelting (often referred to as recycling or downcycling), and those who considered it to be a technological asset with useful potential for reuse. It is difficult to measure, and highly variable among the numerous product categories within electronics, but it is expected that recycling has always exceeded reuse, while both treatments lag behind untreated disposal by a considerable amount (Puckett et al. 2002) (Ontario Ministry of the Environment, 2004). That being said, in relation to conventional recycling, treated disposal is taking some of its share from uncontrolled disposal (negligible levels of treatment in the past make this a certainty) while reuse ,for similar reasons, is thought to be taking a growing amount of its share from treated disposal.

If the processes applied by early recyclers are any indicator, their intention was not necessarily the preservation of the environment, but more unidimensionally the pursuit of profits commensurate with the acquisition and trading of commodities. One deleterious processing pattern which remains prevalent to this day is the export of electronic scrap to third world countries, especially to South Asia and East Asia. What makes this form of processing deceptively benign is that although the waste is purchased as a commodity (usually by weight) only a fraction of the delivered product is desirable and commercially valuable. Essentially, the precious and near-precious metals are desired, while the remainder is once again considered to be disposable. While it is undeniable that society retains the benefits of those precious and nearprecious metals, as the environmental damage and other costs related to their original extraction 
have already been incurred, many issues remain for their safe recycling. The labour standards in many of these countries are unenviable, and are heterogeneously applied within countries, while environmental standards are similar. In many cases, the valuables are extracted under unsafe, unhealthy, and less-than-rewarding circumstances, and the remains disposed of in an uncontrolled manner (Puckett et al. 2002). Without question, harm has been exported; however, just as many services are efficiently off-shored from a job completion and financial perspective. It is by no means unthinkable that e-waste recycling services could also be managed internationally, following investments in the appropriate management systems.

Successive layers of response to the e-waste stream and its early treatments have received increased attention and, with time, more integrated and internationally conscientious responses have been derived to lead the way. The e-waste management solution appears to be at a pivotal point in its development, perhaps at the end of its beginning chapter. There are a few key discriminating factors which broadly differentiate among the various means of e-waste processing. These factors are: (1) commodity recycling vs. technology reuse, (2) embrace of international markets vs. embargo, and (3) incidental vs. maximum environmental benefits. The third factor is somewhat of a curious entry in this schema, as is the international embargo factor, as both of these are in conflict with market forces and what some may call the prevailing natural law of supply and demand. These contrary-to-market factors are driven by a softer, ethical power, which as of yet has a mostly unrealized potential to crystallize into something more generally compelling, forceful, and sustainable. It is this tension and potential synergy between environmental and market forces in the e-waste arena that will be a recurring theme in this report and will be emphasized in the author's recommended Sustainable E-Waste Management System 
(SEMS).

A prevailing position among policy-makers is to have the issue dealt with by funnelling the issue, and its associated equipment, through one agency using one simplified process. As a result of this position, the common response is for policy-makers to charge manufacturers of electronics with the ultimate responsibility for e-waste-within promulgated governmental regulations. Of concern with this approach, both a priori and as evidenced by recently fashionable disposal techniques, is that the most popular treatment of e-waste will be the superficial approach of shredding/dismantling and smelting the materials (C. Thomas, pers. comm., July 16, 2004) (Scott Lindberg, pers. comm., April 3, 2007). This treatment method will certainly remove the equipment from sight; in fact, it will cease to be 'equipment'. The outcome will be achieved at the cost of significant lost opportunity in terms of technology reuse, especially since this technology already includes the original investments of materials, pure water, and energy that went into manufacturing the item. The application of energies towards downcycling items from useful forms to raw materials and ultimately encouraging additional new production via the supply of recycled raw materials is not only destructive of the item's existing value, but also of patterns of material conservation. This introduces a dilemma, half of which must be solved before any ideal long-term solution can be suggested for the e-waste problem. If we are merely to recycle e-waste for its commodity raw materials, we are encouraging a vicious cycle whereby we are only serving to feed a pattern of production and commensurate consumption that is similar to the status quo. Although equipment would be diverted from landfill, which is a key goal, its relatively short lifespan and toxic contents would remain constant. It is these constant factors that, as suggested earlier, are the true drivers behind 
the need for an aggressive, multi-stage program of diversion. Thus, diversion from landfill and optimal end-of-life and mid-life processing options are half the battle: they can prevent contamination of our biosphere via dumping and other unsafe practices, while also significantly extending the life of technology. On the other hand, these end-of-life approaches do not address the toxic dispersions generated during the working lives of electronics, nor do they address the deemed disposable nature of electronics for reasons such as a lack of upgradability, fragility, and consumer patterns, all of which are highly manageable by manufacturers and distributors. The latter factors perhaps weigh more heavily on the environmental outcome of long-term e-waste management, but they are only manageable by foresightful and conscientious design. While some jurisdictions are tackling this design challenge, we are currently faced with the challenge of managing an existing stock of potentially toxic, potentially reused e-waste which will be released for disposal in increasingly large annual flows over the coming years-well before any green design changes will take effect, let alone reach materials at their end-of-life stage. As a result, this report will focus on the more immediate concern of disposing of currently decommissioned electronic equipment, with a specific focus on information technology.

\subsection{Objectives of this Research}

How accurately the basic problem of e-waste is perceived, and the standards against which potential e-waste management systems are judged by decision-making and policy-setting bodies will be key determinants in generating an e-waste solution equal to the task before it. It is in the interest of accurately perceiving the e-waste problem and formulating a solution that is both environmentally and economically sound that the motivation for this research lies. The research has been focused on informing and guiding decision-makers towards a suitable management 
program for the issue. The author recognizes the ailment of contemporary decision-making bodies: in their zealousness to provide decisions they often fail to adequately understand the problem on any level beyond that of a Powerpoint presentation. The focus is often on band-aid solutions and, with respect to environmental policy, decisions are more often economically and politically oriented than environmentally driven.

This research and resulting report have been tailored, thus, to provide readers with a robust set of resources from which to draw their own conclusions regarding the issue of e-waste. The informational basis of this report, the basis upon which subsequent analytic and recommendation components are based, is not only thorough, but also balanced, while clearly striving to uncover those truths most relevant to the proper care of the environment. This report is organized into six major chapters and the progression of chapters has been designed to follow an organic decisionmaking pattern where readers will progress by first learning about the scope of the issue of ewaste, consider general and then specific elements of the problem, be introduced to currently practiced or considered solutions, examine an alternate solution derived from study of and participation in a private firm, Computation Ltd., and finally, analyze the major findings of each section, and review recommendations as to desirable policy and processing paths, as well as recommendations for useful future research.

This first chapter serves to introduce the topic of e-waste in general, to define the scope of this study, to outline the methodology employed in the program of research, and to close with a general examination of several ways in which e-waste ails society. The second chapter will build on the informational foundation laid out in the first chapter and will discuss and summarize some 
of the technological and consumption-based drivers of technology accumulation and disposal. The third chapter will delve into an analysis of the ad hoc disposal outlets which have evolved to 'manage' e-waste, highlighting their strengths and weaknesses. The fourth chapter, following a discussion of the last several years, will consider how various governments are filling the ewaste policy vacuum. The fifth chapter will put forth an alternative model of e-waste management, one that injects a novel element into existing process models that are an improvement over the past, but that continue to demonstrate significant opportunities for improvement. This alternative model, although currently in practice in a similar form at Computation Ltd. ("Computation"), remains on the sidelines of mainstream public and corporate policy. Having presented an examination of the problem from a plurality of perspectives and considering the effects of an ad hoc and governmentally absent approach and a number of existing processing models, the concluding chapter will compare and contrast the key findings of the research, giving readers the opportunity to consider which policy and proceśsing options might best suite their criteria and conditions. Ultimately, this document will aid readers to become more discerning consumers of e-waste disposal techniques, to reconsider what it means for something to be 'waste' (is 'waste' a viable category of material in the $21^{\text {st }}$ century?), and generally to be in a position to reconsider how we should process and consume raw materials and consumer and industrial products given the resources needed for their safe disposal.

\subsection{Research Method}

The research will begin with an examination of general pre-analytic environmental and technological reference points in order to establish a foundation for why the question of e-waste management must be answered. This will aid in determining the value of these answers to 
society (Robinson et al. 1990, 36-46). From there, the research will proceed to consider the origins of computer-centric e-waste and its definitions, current processing practices, industry organization, destinations of final products, trajectory of the management industry, regulations (in a variety of jurisdictions), and manufacturers. A combination of methods will be employed, including policy analysis, case study research, participant observation, waste audits and material disassembly, supply chain and reverse supply chain analysis, and literature review.

The bulk of the study will centre on synthesizing a more optimal system for the management of computer-related e-waste. This Sustainable E-Waste Management System (SEMS) has been evolving in a living laboratory with quasi-experimental status at Computation, a firm whose raison d'etre has been to process as much e-waste as possible. Over the years, a number of policy revisions and added processing options have certainly aided in the growth of the firm, but have also, through careful analysis of client requests, revealed several hidden barriers to increasing the volume of recycled e-waste. The author's role of developing the firm has afforded him the opportunity to learn first-hand not only the processes available for the management of e-waste and the related environmental outcomes, but also the perceptions and policy preferences of potential and active consumers of e-waste management services. These consumers include private sector businesses, governmental and non-governmental organizations, and private individuals.

\subsection{Organization of this Report}

The SEMS discussed in this report, while entirely based on a working model, will be described as it has been functioning, but will include added recommendations for improvement not yet 
scheduled for deployment. That is, the SEMS will be further tailored and improved to achieve an optimally sustainable balance between reuse and recycling, thus also balancing its costs and benefits. This system's processes and outcomes, remaining true to the foundations of this study, will be judged against the same criteria as the status quo; that is, it will be judged with regard to its environmental, social, economic, and technological impact (Thompson, 2002). The abstraction of the SEMS from the context of Computation provides the opportunity to inductively build the schema or template for a more efficient and geographically more pervasive e-waste industry. This template will include the identification of key industry functions, vital organs, links to other industries, and their scalability from the single firm level (Thompson, 2002). To the extent that the SEMS outcomes and style of operation are found to be desirable by policy-makers-when aspects such as reuse are not generally favoured by the primary manufacturers and distributors of new computer equipment-regulations and incentives can be shaped so as to encourage the development of the e-waste industry along the lines of the SEMS. 


\section{CHAPTER 2: THE W5H OF E-WASTE}

\subsection{Drivers of E-Waste}

E-waste is a systemic issue whose origins and impacts span the globe; it exists in our material environment and so it is a problem involving the way in which humans relate to their environment, wherever that may be. The issue is very tangible and takes up physical space. This, in fact, is one of the key issues: landfill diversion. Until recently, one might have thought the environmental significance of a computer or stereo to be quite minor. That the consequence of putting a computer onto one's curb may not have merited further thought was thus consistent. With over $60 \%$ of American households being in possession of at least one computer, European households demonstrating comparable numbers, middle-income countries being in the deciles of per capita ownership, and prominent MIT engineers racing to build the world's first $\$ 100 /$ unit laptops as part of their One Laptop Per Child (OLPC) program for the developing world, the volume and prevalence of these goods is far from being minor, even without the inclusion of corporate possessions (U.S. Department of Commerce, 2004) (British Broadcasting Corporation, 2005). The penetration of computing equipment and its impact, which the following pages will identify, also provides us with a logical understanding of how other product categories pose a variety of generic environmental threats, and how solutions in each category may be leveraged for the more effective management of e-waste and, further still, the integration of environmental management into the disposal processes of related product categories at their end-of-life stages. The understanding and environmental management of e-waste would be encouraged in the interest not only of waste diversion, but also of maximizing long-term returns on extracted natural resources and investments of energy, in whichever form they may arise. 
The evolution of the e-waste management pattern seems to be saturated with paradoxes and dualisms. Throughout this chapter we will see that the drivers of e-waste growth are the diminishing cost of electronics, the rapidly increasing rates of technological improvement, and the increasing acceptance and reliance on IT products in our lives. Along with those factors come increases in demand and willingness to discard, a wider range of possible applications, and product differentiation for greater market penetration. The propensity to discard is inversely related to a product's replacement cost. As new items come to cost less and less, in-use items are discounted even further, and their position as useful goods becomes less secure. As technological capacity advances, production and hedonistically oriented societies will opt for the improved new product, again reducing the value of the previous version. In many cases this relegates the old product to a deemed obsolesence, or at the very least to a redundant second best, due to its inability to support modern applications, whether they be advanced operating systems or the ability to play contemporary games. The ubiquity of electronic products and their advanced market penetration speaks to the integration of sophisticated products into society and plainly communicates that electronics are tightly woven into the fabric of our lives. They are a "must have" item, not in the sense of highly ephemeral fashion, but in the sense that they are part of society's modus operandi. (C'mon, how many of you still use a typewriter?)

The adoption and consumption of new electronic products effectively propels human societies up a hill towards a proverbial peak. While it may be obvious to a person when they have arrived at a point of maximum local elevation, it is not so apparent to a whole society when it is attempting to determine whether a practice is environmentally sustainable. To be environmentally sustainable, a practice must not erode its own foundations or resource base, be they biophysical, 
economic, or social (Robinson et al. 1990, 36-46). This obscured perception of society's is especially evident when a group has been trained to govern itself according to the availability of a single abstract measure, such as money, to determine whether all other resources can be acquired. The key disjunction is that all other resources, with the exception of solar energy (whose daily inflows are also quite definite), are fruits of the earth, and hence finite, while currency is created by political fiat which as of yet has not tied monetary policy to any environmental concerns, including the availability of resources. The hill we are thus compelled to climb sets the stage for our arrival at a peak and begs the question "Where is the top?" This question can be framed in a number of ways as it relates to electronic products, such as:

- When do electronic products become waste? (an implied certainty)

- When should electronic products become waste? (a less passive position)

- Why should electronic products become waste? (an empowered position)

Which of these questions are asked and which position is presumed in examining any issue tells us much about the objectives of those asking the questions. When the top of a hill has been reached, a reflex response may be to descend down it and enjoy the ride, perhaps the equivalent of creating physical waste. There may be other options, however, which can include appreciating the view or seeking out and ascending other peaks for their various virtues, preferable elevations, climates, habitat, or neighbours. Ultimately, this consideration of options translates into a consideration of how to manage the pool of resources that have been invested in the ascent. It is as we ascend and come to understand this hill of technological accumulation that we have the opportunity to consider why we accumulate, how we do it, how we may do it better, and what 
our final destination should be. Granted, the answer is a moving target. All of these considerations that lead up to the peak or decision point, and the postulated questions asked at that point, invariably set the framework for the other half of our travels; that is, how we will navigate the path beyond that initial peak.

The factors of cost, technological adoption, and ubiquity of product are the drivers behind why we accumulate; they are also the drivers behind why we waste. The factors have been distilled from observation of IT product development, IT market development, and the decision by consumers to dispose of IT products. In assessing e-waste management practices used currently and those suggested as future alternatives, an understanding of these drivers will be key, as will be an understanding of the main impact of improper e-waste management practices. While it is recognized that improper waste disposal will have harmful environmental side-effects, underpinning this study is a recognition that minimizing harm is a highly reactive and limited perspective, where maximizing opportunities can not only prevent pollution, but can also leverage resources to greater ends. Assessing the depreciation of technology and its residual value with accuracy, differentiating between a mass of materials and a finely crafted tool, and recognizing that while cordless tools are quite handy, cabled power tools and hand tools still have considerable utility, are all key to optimal e-waste management. The implications of these considerations will be examined in greater detail within the context of a recommendation for a system of reuse discussed later in this report.

\subsection{Scales of E-Waste}

The degree to which computer equipment had penetrated households, coupled with the 
consumerist translation of Moore's law that computing power will double every 24 months, suggests that as computer processing power doubles with regularity, consumers will keep up with technology, although volumes of adoption and turnover will likely decline as the number of first-time buyers diminishes (Intel Corporation). As a result, consumers will have impetus to replace their stock of computing equipment every two to three years or more conservatively every three to five years (Long, 2004). If one takes the number of individuals in any jurisdiction (I), multiplies this number by the penetration rate of computer equipment or other electronics (P), and multiplies that figure by the inverse of the average ownership tenure of a product in years (1/OT) the concluding value is the average number of products to be destined for disposal (EW) in a given jurisdiction in a given year. The formula can be summarized as follows:

$$
\mathbf{E W}=\mathbf{I} * \mathbf{P} *(\mathbf{1} / \mathrm{OT})
$$

As the formula illustrates, a large quantity of material and product value depreciation takes place each year. If one takes the USA as a key example of great relevance to the Canadian case the final figures prove staggering while employing conservative figures. By the equation above:

- I = 298 million 2006 est. (Central Intelligence Agency)

- $\mathrm{P}=60 \%$ (U.S. Department of Commerce, 2004)

- $1 / \mathrm{OT}=1$ years $/ 5$ years $=0.2($ Long, 2004)

- $\mathrm{EW}=298 \mathrm{M} * 60 \% * 0.2=35.8$ million computer systems destined for disposal each year in the USA

Using a 10:1 rule of thumb Canada might expect 3.6 million computer systems destined for disposal each year. 
This discussion has focused on the macroscopic picture which has great utility in providing estimated aggregate figures for policy-makers focused on e-waste and related issues. Answers to macroscopic questions provide a sense of scale to an issue, and a sense of the structure, in this case, of the material stream. To anticipate the elements of processing that the e-waste equipment requires, there is a need to zoom in and have a closer look at the geographic distribution of equipment, the specific makeup of each device, and the finer details of consumer and technophile behaviour.

\subsection{Production and Consumption of Electronic Products}

The mass of electronic equipment produced to date has followed the path of industrial development and the parallel growth of mass consumerism and urbanization. Much of the material that is a precursor to e-waste begins its useful life in cities, and these cities, as of the year 2008 will represent $50 \%$ of the world's population (Worldwatch Institute). Prior to that useful life and during its manufacture, the equipment consists of quantities of unmoulded lead, glass, plastic, steel, aluminum, copper, trace amounts of precious metals, and various other chemical additives such as poly-brominated-biphenyls (PBBs), which are applied as fire retardants to circuit boards, Table 1 below contains a frequency list describing the $\%$ by weight material composition of a typical PC. 


\begin{tabular}{|c|c|c|c|}
\hline \multicolumn{4}{|c|}{ Table 1: Material Composition of PCs } \\
\hline Material & \% Weight & Material & \% Weight \\
\hline Silica & 24.88030 & Bismuth & 0.00630 \\
\hline Plastics & 22.99070 & Chromium & 0.00630 \\
\hline Iron & 20.47120 & Mercury & 0.00220 \\
\hline Aluminium & 14.17230 & Germanium & 0.00160 \\
\hline Copper & 6.92870 & Gold & 0.00160 \\
\hline Lead & 6.29880 & Indium & 0.00160 \\
\hline Zinc & 2.20460 & Ruthenium & 0.00160 \\
\hline Tin & 1.00780 & Arsenic & 0.00160 \\
\hline Nickel & 0.85030 & Selenium & 0.00130 \\
\hline Barium & 0.03150 & Gallium & 0.00130 \\
\hline Manganese & 0.03150 & Palladium & 0.00030 \\
\hline Silver & 0.01890 & Europium & 0.00020 \\
\hline Beryllium & 0.01570 & Niobium & 0.00020 \\
\hline Cobalt & 0.01570 & Vanadium & 0.00020 \\
\hline Tantalum & 0.01570 & Yttrium & 0.00020 \\
\hline Titanium & 0.01570 & Platinum & Trace \\
\hline Antimony & 0.00940 & Rhodium & Trace \\
\hline Cadmium & 0.00940 & Terbium & Trace \\
\hline
\end{tabular}

(Source: Meinhardt Infrastructure \& Environment Group, 2001)

The extraction of raw materials necessary for the manufacture of electronics comes with its own, often unaccounted for and unpaid, environmental cost (Diamond, 2006). Ample research has been conducted on the effects of mining and early-stage raw material processing. For a more thorough understanding of these costs, readers are directed to studies focusing specifically on that subject. For the purpose at hand, it is sufficient to provide a summary of some of the more well known side-effects of raw material extraction and processing. These side-effects include the following:

- landscape destruction

- deforestation

- disruption of soil systems and encouragement of erosion

- destruction of habitats

- disruption of wildlife systems

- contamination of surface environments with mined materials and taillings 
- significant energy consumption

- exposure of humans to various safety and health hazards

Later steps of material refining shift their emphasis from primary extraction and its effects to manufacturing, where relatively raw materials are taken into a manufacturing or other industrial setting that is somewhat insulated from the more apparent connection with nature that exists in extraction. The unintended or undesirable environmental consequences of this phase of economic activity, while not always as direct or obvious, are certainly not less significant. The refining and light manufacturing phase of activity has more pronounced effects on the contamination of surface environments, energy consumption, and exposing humans to safety and health standards, with the additional demand of significant quantities of relatively pure fresh water. The total energy used in producing one desktop computer system is $7,340 \mathrm{MJ}$ or $290 \mathrm{Kg}$ of fossil fuel equivalent, the amount of water used/sullied in producing a single memory chip is $36 \mathrm{Kg}$ and over $1,500 \mathrm{Kg}$ of water for a complete computer (Williams, 2003) (Kuehr and Williams, 2003). Up to this point, the originally sought-after raw materials have had considerable value added to them, value that is not entirely reflected in their market price. For example, clean water is hardly metered in developed and developing nations where it is used most, and/or its market price is often negligible (Renzetti, 2005). The disruption of ecosystems has not yet found expression in commonly used or accessible algorithms for its conversion into dollar terms, nor has the diminished biodiversity of an area or the long-term environmental risks of more fragile humansupporting ecosystems been fully monetized. To the extent that these consequences have been ignored or not fully considered, and the extent to which the cost of full remediation been accurately evaluated and accrued as liabilities in public and private accounts, the cost of 
naturally occurring materials has been considerably underestimated.

The consumption of energy in these processes, both electrical and human, involves similar underestimations of its value if one examines the sources of these energies. The unintended and incompletely accounted for environmental consequences of energy production are similar to those of raw material extraction. If one considers the impacts of industrial farming techniques (which is the source of energy for humans) and the associated application of chemical fertilizers and genetically modified products on soil, ecosystems, energy use, and water consumption, it is readily recognized that inputs into this process carry an environmental burden in addition to their harmful environmental effects. The inputs into the inputs themselves will also have their own profile of environmental load and harm. Similarly, the effects of burning fossil fuels needs no introduction, whether the concern be air quality or global warming. The focus here is not to quantify, or even fully inventory the long list of environmental linkages that electronic products or almost any sophisticated product will maintain, but simply to convey the scope of unaccounted for or poorly accounted for environmental investments already placed in a product well before it reaches homes and offices. The consequence for decision-makers is that the management of these sunken and hidden environmental costs are neglected at all stages of the product and resource life cycle, and the return on these investments will similarly suffer.

After much input into various marketing and delivery processes, this equipment resides for a brief period in homes and offices where it is environmentally much more benign than in the open environment, with key exceptions being the electrical energy required to power the equipment and human exposure to materials still off-gassing or otherwise contaminating spaces, if only with 
trace amounts (McDonough and Braungart, 2002). Eventually, this material comes to rest in the closets of individual homes or in the storage lockers of IT departments for a temporary holding period, until demands for private space spikes and spaces must be liberated. The result is spikes in the outflow of e-waste according to a number of possible schedules of corporate and household investment and disposal. Over the long-term in the electronics and IT industry, product tenure periods may lengthen, thus diminishing demands for disposal. While that may be true within static product categories, other categories are often overturned completely as part of the creative destruction process.

\subsection{Driving the Technology Waste Cycle}

It is often cited that the advent of Liquid Crystal Display (LCD) monitors dramatically reduced the value of used Cathode Ray Tube (CRT) monitors, which is a considerable shock to systems of reuse management. However, just as LCDs have replaced CRTs, it is expected that within a generation a new version of display will replace the LCD variety-perhaps electronic paper or some similar variant. What this means for CRTs, as it will for LCDs, is that while the cost of manufacture will remain constant, the trendiness of the technology will diminish, creating a commensurate discount on the market value. This will have a parallel effect on the used market: prices will drop to clear the available supply. Following some lag period, and this will relate to the expense of the product, increasing volumes of LCDs will require repair and, eventually, when larger LCDs become more affordable-perhaps as computers and home entertainment systems converge-the smaller and older LCDs will appear in the end-of-life stream, with a final bulge in volume when they are altogether replaced by an alternative. The logic of this product life cycle applies to computers as the various internal components which make up the 'box' are 
improved in minor, moderate, and major ways; similarly, though less voluminous materially (while households often have a 1:1 computer to printer ratio, formal organizations do not) this product life cycle also applies to the broad category of printers.

PCs have undergone several generations of change. To illustrate the degree of changes that have occurred, comparisons to the development of the automobile have been made. If the automobile's development in terms of fuel efficiency had matched that of computer performance increases, be it in terms of processor speed, memory size, or hard disk size, fuel tanks would be the size of petri dishes and both oil shortages and vehicle emissions would not be of concern (readers are encouraged to recall the specifications of their first computer compared to the one they use today). Not only have the sheer numeric capacities of these and other parts changed, often the material used for construction, for reasons of expense or performance, and the physical structure of the device have changed quite radically. For instance, central processing units (CPUs) on conventional desktop computers, up until Intel's release of the Celeron processor, were exclusively 'printed' on ceramic structures. From the Celeron onward, another key change took place: the quantity of gold and platinum group metals used in the construction of CPUs has dramatically decreased. Overall, their performance has increased dramatically, the raw material value of the processor has decreased, their size has decreased, and the amount of heat they generate has rapidly increased, requiring larger copper and aluminum heat sinks and energy for fans and cooling systems (participant observation from 2001 to 2007). Power requirements from the days of the Pentium I were in the range of $100 \mathrm{~W}$ to $200 \mathrm{~W}$ for the desktop or tower computer, not including monitor or printer; today, typical power requirements range from $300 \mathrm{~W}$ to $450 \mathrm{~W}$, with many going well beyond this number (participant observation from 2001 to 2007). 
With each generation of major processor (to this point Intel releases have included the 8080, 286, 386, 486, Pentium I, Pentium II, Pentium III, and Pentium IV), the previous generation's motherboard is rendered obsolete, or, more accurately, it cannot efficiently accommodate the new generation of CPUs by design. Please note the changing pin configurations in the successive generations of Intel CPUs shown below in Illustration 1.

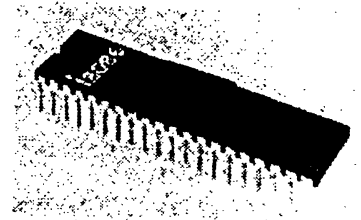

8086

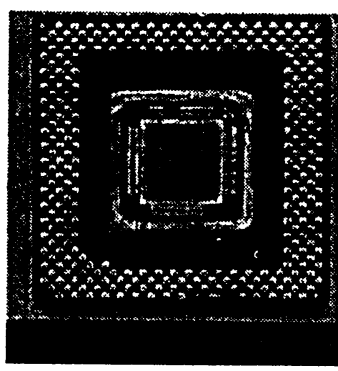

Pentium I

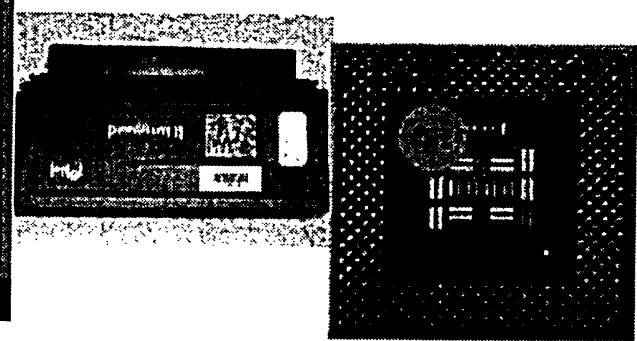

Pentium II

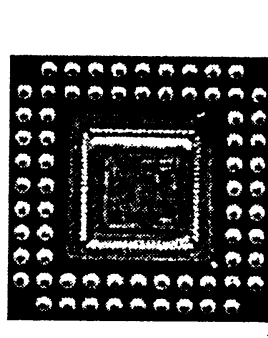

286

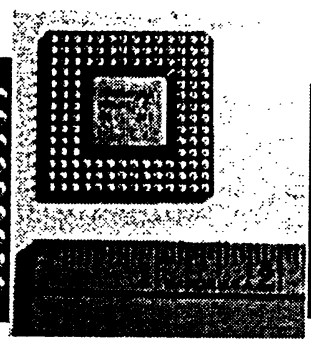

386

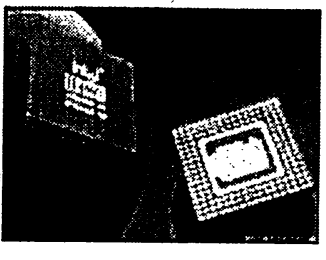

486

\section{Illustration 1: Intel CPUs}

Top from left to right: Intel $8086 \mathrm{CPU}, 286,386$, and 486.

Bottom from left to right: Intel Pentium I, II, III, and IV.

(Source:pcenc.atspace.com/processors.htm, 2007)

These generational changes of computer processors partially drive the development of e-waste, as do similar generational changes of computer memory. (Types of memory to this point have included SIMM, DIMM, SD-RAM, RD-RAM, DDR1, and DDR2, and types of hard drives have included IDE, SATA-I, SATA-II, and SATA-III.) The motherboard, as the name connotes, is the 
'female' connector to all other devices which are employed in the computer, and thus a costly item to replace. Motherboards themselves experience secondary change due to the aforementioned upgrades manifesting in new power requirements and commensurate changes in power supplies, which are one of the few items that change somewhat infrequently. The joint cost of the part requiring replacement and the subsequent need for a new motherboard is high enough to prompt consumers to buy a completely new system for just two to three times this amount. In other words, an economy-class version of a new system by a major manufacturer can cost as little as $\$ 400$ to $\$ 600$ (Dell Inc.) (Hewlitt-Packard Development Company, L.P.).

There are a number of competing definitions for when the computer became a mass-market item. Microsoft is 30 years old and the Personal Computer (PC) which it helped popularize through its development of the user interface known as the operating system has turned 25 (The Economist, July 27,2006$)$. Needless to say, as production volumes increased, product prices declined. In the early days of Microsoft, 1976, a basic personal computer such as the IBM 5100 Microcomputer would have cost between $\$ 7,500-\$ 20,000$ USD depending on the configuration (PC World, 1999). By early 1999 that amount had dropped to $\$ 2,999$ for a Dell Pentium II $400 \mathrm{Mhz}$ unit with 128MB RAM, 9GB hard drive, 17" monitor, and inkjet printer, bringing computing technology within reach of a much larger proportion of society (Globe and Mail, January 18, 1999). Prices have continued to drop, and today the price for a common computer system hovers at around the $\$ 500$ mark, while laptops are approximately double the cost and a tenth of the material weight. (an entire desktop system, including monitor, PC, keyboard, and mouse weighs approximately $28.25 \mathrm{~kg}$, while a laptop weighs approximately $3.2 \mathrm{~kg}$.) (Dell Inc.) (Hewlett-Packard Development Company, L.P.) (participant observation from 2001 to 2007). It is this decline in 
price that has led to current trends such as having two or three simultaneously operating computers in a household, partly for establishing home networks, as well as the relatively recent convergence of traditional computing functions with home entertainment and household management, and the increase in the popularity of the home office and telecommuting. While consumers are now able to have more and do more with technology, it is the commodity (versus luxury) pricing that has greatly changed the manner in which consumers maintain their ownership. While basic math would almost universally lead to repair in the early days of computing, today the cost of labour and, to a greater extent, hardware prices, have increased enough to make the decision to repair or replace a much more fickle matter and increasingly points to the replacement option. That being said, a part's longevity varies a great deal. Monitors, for example, have consistently outlasted several generations of PCs, the latter being more fragile and more exposed to potential harm, while the former are simpler, of more robust design, and generally less exposed to multiple inputs and points of interaction than the PC itself.

The current of technological adoption runs along similar veins. Whether the owner is a business or a residential user, informational technology is purchased for an effect. With great variability, the effect is more or less commonly accepted as desirable, such as productive outputs or entertainment value. There are, of course, also effects such as ostentation which are often desired. Whenever these are seriously desired outputs, regardless of how valuable they are to society more generally, the notion of progress finds a welcome place. If a consumer desires an outcome and expects to require a tool to achieve it, then the tool derives a value from its ability to facilitate the attainment of the desired outcome. New and improved tools are hence preferred to older ones as long as they are convincingly attached to the promise of increased goal 
attainment. Businesses want to do more business, those who wish to be entertained certainly prefer more to less, and simply keeping up with peers calls for more and not less in most circles.

Technological advances and decreases in price both change consumers' perceptions of what qualifies as bona fide technology. Today, the term obsolescence has entered everyday usage and, due to price movements, the computer has become a commodity item. As with most commodity items, consumers readily allow technology to enter the waste or general recycling stream with little thought. However, due to various environmental and humanitarian efforts, awareness of the end-of-life impact of such items is becoming more commonplace, although in practice it appears that the bulk of material exits its useful life with inadequate treatment or in an entirely uncontrolled manner with respect to the environment (Puckett et al. 2002) (Greenpeace, 2007). These impacts will be the subject of analysis in the following chapter, but, prior to engaging that subject, it is necessary to summarize what we have discovered about technology in its first incarnation.

Technology employs valuable materials in the body of the good, in consuming inputs during its manufacture and raw material extraction, and in diminishing the availability of other less wellaccounted for environmental goods. The cost of these goods being what it is, few will suggest that the resulting technology lacks value; it serves many functions, not the least of which is weaving together human societies across networks that span the globe. The means by which we have valued aging technology certainly follows a steep curve, one that, perhaps more often than necessary, leads us to the conclusion that certain possessions retain negligible value. This discounting is somewhat surprising and inaccurate since, by classifying used or older electronics 
as waste, a considerable opportunity is foregone. Not only are there direct opportunities in the reuse potential of the equipment and the value of the materials, but there is also the opportunity to alleviate two broad types of environmental pressures, including the unaccounted-for damages to the environment levied by extractive and manufacturing processes related to virgin raw materials, and the environmental damages associated with the uncontrolled release of e-waste into the environment. In conclusion, while electronics are not highly valued at the end of their first useful life, they do have considerable residual value in terms of their reuse potential as a working product, the recyclable materials they embody, the diminished environmental externalities which recycling entails by reducing the need for extraction and its damages, and the derived value of preventing environmental harm through avoidance of improper disposal and its polluting effects. 


\section{CHAPTER 3: IMPACTS OF AN INSUFFICIENTLY MANAGED PROBLEM}

\subsection{Introduction}

While the previous chapter focused on the precursors to e-waste and the production- and consumption-related environmental aspects, the current chapter will focus on the postconsumption aspects of e-waste, including the opportunities in reuse and redistribution, the polluting impact of improperly disposed materials, and the environmental efficiencies associated with the recycling of post-consumer materials. Each of these elements has distinctly local, regional, and international characteristics. Until recently, the post-consumer phase of e-waste could be described as highly disordered, both with respect to the physical concentration of equipment and to the standards of management with respect to the environment. Until very recently, the predominant mode of end-of-life disposal was landfilling either directly or indirectly via exportation to less-developed countries where minimal material reclamation takes place prior to landfilling or random dumping.

Prior to the emergence of some of the more environmentally viable and thorough e-waste management systems, end-of-life electronics followed a very different set of paths to their final resting places. There have been four traditional pathways to the disposal of electronics, as follows:

\section{Traditional E-waste Pathways}

1) direct or indirect disposal via hazardous commodity export to less-developed nations

2) local landfilling or dumping

3) resale/reuse 
4) semi-permanent storage

The origins of current processing methods can be found in the four traditional e-waste pathways noted above.

\subsection{Direct or Indirect Disposal via Hazardous Commodity Export to Less- Developed Nations}

The outlet which has received some of the most pronounced attention has been the export of ewaste to less-developed nations (LDNs), mainly in South Asia and East Asia. This material flow is directly related to the supply of inexpensive labour in these LDNs. The reasons for the lower labour costs in these places are many-fold; it can be as simple as the volume of the available population, which could be suggested as both the cause and the effect with respect to the ability to create and enforce labour, health, safety, environmental, and other regulations. This is a double-edged sword as relates to the environment. It means there are more people put in a position to do greater harm to the environment by acting in avoidance of or in the absence of regulations. This is further exacerbated in the case of China; as its economy has shifted from a command-style to a market-driven basis, the demand for raw materials has surged at an accelerating pace, causing a tightening of supply and commensurate increase in prices, both locally and globally (Goodman, 2004). While this is perhaps not so much an oversimplification as it is a very brief summary, as a result of these economic facts, an opportunity was recognized by South Asian and East Asian entrepreneurs. Raw materials of all varieties (precious metals, copper, aluminum, and even plastic) could be acquired in post-consumer form such as e-waste and, due to the low local labour costs and accompanying low levels of regulation, could be 
processed into usable form employing labour-intensive methods of material recovery in highly uncontrolled environments. The effects of such processing on the environment and on the people involved is plainly horrific. Considerable efforts have been made to study and document the effects of such processing methods and patterns; internationally, the principal investigators have been the Basel Action Network (BAN) and the Silicon Valley Toxics Coalition (SVTC) (Puckett et al. 2002.). The images in Illustration 2 below are courtesy of BAN, and demonstrate the uncontrolled handling of e-waste which is rampant in less-developed countries, predominantly in South and East Asia.
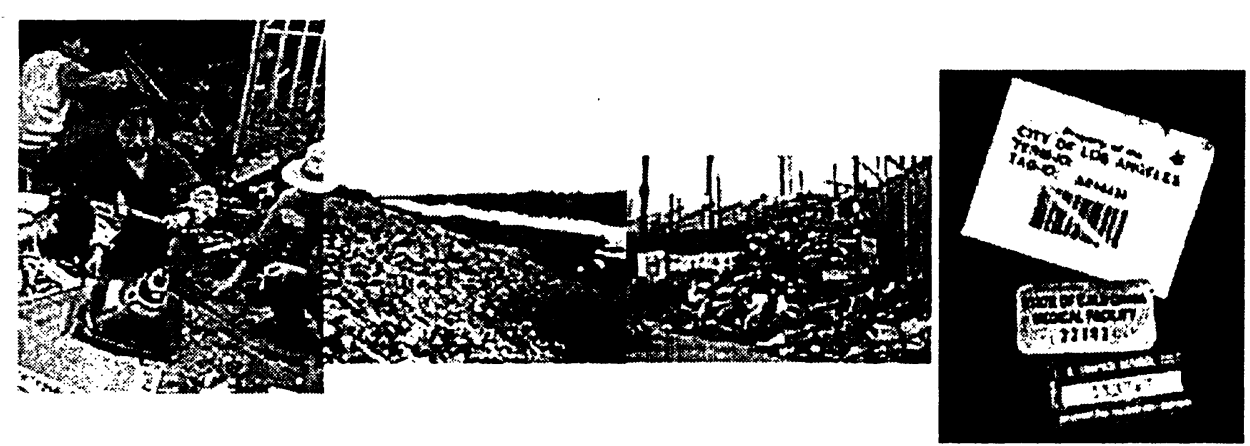

llustration 2: Uncontrolled Handling of E-waste (Source: Puckett et al. 2002)

BAN arose from the Basel Accord, an international treaty banning the export of hazardous wastes to countries that are not part of the Organization of Economic Cooperation and Development (OECD) (Basel Action Network, 2005) (United Nations Environment Programme, 2006). (See Appendix 1 for a complete list of signatories and see Appendix 2 for those countries which have ratified the accord; Canada is among both.) While the accord has been agreed to, there is no local enforcement of the export ban, evidenced by the regular solicitations received by Computation to this day for the export of shipping containers holding tens of tonnes of 
'electronic scrap'-these requests are not merely for a single container, but for multiple containers on a monthly basis as part of an annual contract. While there is a regulatory vacuum for the enforcement of the Basel Accord, there is relatively strong, if less precise, public-market pressure in favour of the ban. It takes the form of ethical consumers screening their recyclers and asset managers to ensure that their waste is not inappropriately exported. This conscientiousness has a trickle-up effect in that some recyclers and asset managers have thus screened their end markets for these same human and environmental health concerns. This pressure has grown with public awareness and can be measured by, if nothing else, the large and growing amount of media discussing the hazards of e-waste processing in LDNs. The result is that the number and scale of firms involved in material processing that could ignore, buffer themselves from, or only pay lip service to such pressures has greatly diminished.

\subsection{Local Landfilling or Dumping}

Local landfilling and dumping brings the matter of e-waste closer to home. There are three major differences between this outlet and that of export. Local landfilling ensures that there is no positive gain from the end-of-life processing of e-waste through material recovery (economic or otherwise), there is no incineration or other deliberate or active method of processing the materials, and the materials generally remain in the region in which they were originally consumed. Materials end up in landfills with only the most minor economic element to their transaction; an agent is paid to deliver them to a landfill and a 'tipping fee' (approximately $\$ 50$ per tonne for transport and tipping) is levied against the agent or principal for the right to dump broad categories of material into the landfill (Sheppard, 2006) Landfills in North America have grown increasingly unpopular from the public standpoint, and, it must be noted, site selection, 
design, and technologies employed in North American landfills are much superior to the uncontrolled dumping which occurs in LDNs. While these factors do curb the harm of landfilling, the contents continue to contaminate local soils and leach into groundwater supplies (Uryu, Yoshinaga, and Yanagisawa, 2003) (Jang and Townsend, 2003) (Osako, Kim, and Sakai, 2004) (Macauley, Palmer, and Shih, 2003). The general disapproval of landfilling and commensurate shortage of sites has led constituencies like the City of Toronto to strive for a $70 \%$ diversion of general waste by 2010 , that said, they have also recently secured their own direct ownership of a regional landfill site (City of Toronto, 2007). While this is a more positive approach, other constituencies have moved more decisively by banning local landfilling of ewaste: the town of Stratford is a rare Canadian example (City of Stratford, 2007). Progressively, the holes in the system are being plugged.

\subsection{Resale/Reuse}

The resale and reuse of IT-related e-waste has been present since the original emergence of computing products. This process takes many forms, most of which are commendable; however, there are conditions under which this category of disposal merges with that of the exporting. Electronics retain their residual reuse value in inverse relation to their age and in direct relation to their working order. The size of this residual value for each unit in a batch, both in absolute dollar terms and as a percentage of the original cost, as well as the perceptions regarding the continuing usefulness of each unit, do much to determine the details of if and how the equipment is reused. Unlike landfilling which, though increasingly unpopular and uncommon, is generally always available to single users, the infrastructure for resale and reuse has not always been so evident to potential users. Instead, the pathway to export end-points has always been murkier and 
has a longer list of intermediaries; the length of that list translates into a lack of transparency which in the early days of e-waste would have made it difficult for a consumer to realize that the end-point of their waste was offshore dumping. Early computing equipment servers and mainframes would have had limited application, so reuse and resale would have had limited potential, though the residual value would be much more resilient than it is today, often leading to the semi-permanent storage option. As use became more widespread, asset managers appeared on the scene to manage the resale of such valuable items. As computing became democratized with the advent of the PC, applications for its use grew manifold, but market penetration of the PC remained low. As a result, reuse in organizations, families, and other small communities would bridge the digital divide that had arisen between first adopters and early adopting minorities, continuing onward through the ranks of technological adoption until various thresholds of saturation were reached. Once PCs became relatively common, institutions were required to channel these masses of useful equipment to those external groups who had yet to benefit from the trickle-down. And all the while PC prices were declining. The result has been that a variety of institutions have been created, including not-for-profit agencies committed to the social redistribution of working and near-working equipment that is donated to them, employing and training the under-employed in the process (Computers for Schools, and reBoot are Canadian examples); asset managers that broker the sale of high-value and off-lease items (such as Midrange Inc.); and online sites like eBAY that have advanced the capacity of nimble individuals to remarket their used goods in similar fashion (participant observation from 2001 to 2007). This ad hoc system of resale and reuse has certainly stemmed the tide of improper e-waste disposal; however, a number of shortcomings are apparent. Voluntary organizations interested in the social redistribution of working goods do not always have environmental protection as part of 
their mandate, nor do their resources typically place them in a position to adequately achieve this protection. Similarly, asset managers are in the business of merchandising so when they encounter non-working, irreparable, or obsolete equipment, it often enters one of the other ewaste categories.

\subsection{Semi-Permanent Storage}

The existence of the storage category is somewhat remarkable in itself. The items placed in storage, especially in the IT or electronics category, are generally known to be working, and hence not thought to be waste or otherwise suitable for permanent disposal. Instead they collect dust with the hope that they might be used again one day. For most units that day never comes. This is particularly anathema to the contemporary business mindset with its adoption of just-intime inventory management systems and the apt recognition that paying for the storage of a useful or value-bearing asset is simply a waste. With the increasing prevalence of new and improved models of e-waste disposal options taking hold, it is expected that this last category of e-waste has diminished.

These traditional pathways for e-waste give cause for the derivation of an improved management system in two broad ways. The first is a response to the ad hoc nature of current 'solutions,' not in terms of their considerable variety, but rather the unsystematic nature of that variety. Without striving for over-planning, it is intended that well-informed and concerted policies and guidance would help shape an integrated industry capable of a thorough e-waste solution. The second is a simple drive to espouse standards; there is currently a pronounced lack of standards for e-waste processing, regardless of the approach. The four pathways for e-waste describe very different 
methods, each with its own balance of costs and benefits, and perhaps each with some part of a viable process that could be developed and, more importantly, connected with the others into a vertically integrated e-waste management structure. Exactly which direction the process developments take and which processes are considered desirable and merit inclusion into a larger structure is the matter of higher-level policy debates that consider a plurality of the concerns of their citizens, stakeholders, and vested interests, both public and private. 


\section{CHAPTER 4: CURRENT PUBLIC POLICIES ON E-WASTE AND THEIR TRAJECTORIES}

\subsection{Introduction}

The previous chapter's examinations provided passive summaries of what has been taking place with regard to e-waste; the conclusions of those summaries convey that e-waste has generally been responded to in an ad hoc manner that lacks standards and general applications across the largest jurisdictions. This chapter thus marks a turning point in the report from a passive summary to a forward-looking, critical policy-level analysis, and gives recognition to contemporary societies across the globe that have recognized that e-waste is a problem of regional, national and international scope. In this chapter, the continuing problem of e-waste is additionally defined as a problem of policy, exacerbated by earlier lacklustre responses. Given the scope of the issue, the failure of ad hoc, market-based, and unregulated responses demands that the problem of e-waste be dealt with by levels of government appropriate to the problem. Various jurisdictions have involved themselves in the solution, while others have not. The major players are governments and manufacturers of the equipment which is becoming e-waste. The key predictor of the strength and, more importantly, the effectiveness of e-waste management policies and regulations is the power of a government or state to design, promulgate, enforce, and monitor. Conversely, the corruption of both the public and private sectors mitigates such power. The focus of the analyses here are the states and entities listed below.

\section{$\underline{\text { States and Entities with Active and Significant e-Waste Considerations }}$}

- The Basel Accord

- The European Union

- China 
- The United States

- Ontario, Canada

Included in discussion of each of these units, where appropriate, will be the role and efforts of manufacturers. The above jurisdictions span a variety of types and represent quite different parts of the world. Commensurate with this is that each jurisdiction is faced with its own relatively unique reality with respect to e-waste and has thus developed, or is in the process of developing, its own unique response.

\subsection{The Basel Accord}

As introduced in the previous section, the Basel Accord was created to combat a systemic pathology that arose with turn-of-the-millenium globalization and its peculiar patterns of trade. Essentially all manner of waste material, from dillapidated war machines, radioactive materials, and used electronics was and continues to be shipped across a large number of borders to final 'processing' destinations in LDNs. These shipments proceed under the assumption that both parties to the transaction are capable of handling the materials in question to a recognized international standard. The concern with these transactions, for proponents of the Basel Accord, has been that in many (if not most) cases the nature of the trading relationship between the nation of origin and the receiving nation has been highly asymmetrical, particularly with regard to the environmental impacts of the transaction. What often occurs in such trading relationships, for the largely economic reasons documented in the previous chapter, is that the firms in the LDNs receive the waste or residual materials from the firms in developed nations. Due to the highly pro-trade policies of the developed west and the limited regulatory capacity of LDNs, these 
transactions carry on unnoticed. Historically, they have not captured the attention of authorities since on the export side these transactions are usually recorded as relatively low-value sales, considering the residual nature of the materials. On the receiving side, the transactions have been recorded as commodity acquisitions. For the most part, neither side would record the transaction as the sale and purchase of waste, as it would be easier to complete the transaction without regulatory hurdles to surmount. This pattern of transactions continued until the evidence demonstrating its existence and impact became undeniable, resulting in entire villages and stretches of coast or valley being contaminated by the remnants of waste that has been stripped of its most valuable materials and dumped. Not only are the undesirable materials discarded with complete abandon, but the processes used to recover the valuable materials are extremely inconsiderate of human and environmental health. Considering the precursors which gave rise to this situation-namely, an abundance of and a growing appetite for certain materials in the developed world, combined with a lack of capacity in LDNs for their safe processing and a similar lack of regulatory controls to manage inflows of said materials-the conclusion among concerned nations was that the most effective means of stemming the damage caused by these transactions was to cut them off at the source. The export of waste from OECD countries to nonOECD countries would be banned. This, if thoroughly implemented, would protect LDNs from inadequate processing practices and would encourage the west to manage its own waste and develop homegrown processing solutions. Of the 169 countries which have signed the Basel Accord, 63 have ratified it in their domestic governing institutions (United Nations Environment Programme, 2006).

Discouragingly, the same lack of regulatory capacity which plagued transactions between 
developed nations and LDNs before the Accord is now apparent in the OECD as well: the contamination in LDNs continues to grow, evidencing the continued export of e-waste from OECD countries. In developed countries that are so adamantly trade oriented (while many LDNs are increasingly so inclined) and with economies as large as they are, the time and cost required to inspect each shipping container to ensure compliance with the BA and other trade-related laws would so hinder trade that this may well be the de facto explanation for why it is not done. The thousands of containers that go unchecked while awaiting either loading onto ships or pick-up by receiving agents at any given transit point on any given day indicates regulatory difficulties quite clearly. Nevertheless, the BA and similar laws have made it marginally more difficult for those who would be involved in the trade of e-waste, given its ostensible illegality in countries that have ratified the accord. It is expected that the most likely means by which the intentions of the BA will be realized is through the local processing of e-waste in the jurisdictions in which it is first disposed, following efforts by regional governments to encourage the tendency of consumers to recycle, the development of processing capacity by industry, and the enforcement of responsibility on manufacturers. The Basel Action Network (BAN), an advocacy group made up of not-for-profit and non-governmental organizations formed to support the public interest and BA principles, continues its efforts with regard to improving ratification and compliance with the BA, and also with the development of 'Basel-Friendly' local e-waste processing capacities (Basel Action Network, 2005).

\subsection{The European Union}

The European Union (EU) was among the first state bodies to develop a systematic and environmentally sensitive policy surrounding the end-of-life treatment of Waste Electronic and 
Electrical Equipment (WEEE). Coming into effect July 1, 2006, the EU's WEEE policy directives will require that EEE manufacturers provide free recycling programs to consumers and remove various heavy metals and hazardous chemicals from the material components of EEE, thereby eliminating WEEE from the waste stream, and factoring waste management considerations into the design of EEE (European Commission, 2007). Incidentally, the EU developed its Restriction on Hazardous Substances (RoHS) policy along a similar timeline. This policy prohibits a list of substances from being employed in the manufacture of products by companies based in the EU, or in products to be sold in the EU, the substances include: lead, mercury, cadmium, and hexavalent chromium) and brominated flame retardants (polybrominated biphenyls (PBB) or polybrominated diphenyl ethers (PBDE) (European Commission, 2007). Aside from its thoroughness, which will be discussed in greater detail, the EU policies are of great relevance because of its extra-territorial implications. Due to the size of the European market, its policies hold sway over decisions made by firms around the globe. For example, in July of 2006, Computation was contacted by a Canadian firm which produces passport readers for use in European airports (participant obersvation from 2001 to 2007). The EU requires that at least $60 \%$ of the weight of each passport reader is recycled at end-of-life, a standard that is required of all firms producing electronic goods for use in the EU. This is of particular relevance to multinational manufacturers such as the major computer brands. If a significant portion of a firm's market is governed in an environmentally strict manner, a foothold is created for stronger environmental policy throughout the firm, not only to influence corporate culture, but also to develop the standards to serve the EU and similarly governed markets. The standards that a firm develops to serve its primary markets can also serve the remainder of its markets, perhaps even encouraging the development of environmental regulations by weaker states that rely on 
international organizations like the EU and BAN to pave the way with their regulatory breakthroughs.

\subsection{China}

The bulk of China's relevance to e-waste management is in its status as the prime example of the impacts of uncontrolled e-waste processing in LDNs as discussed in reference to the BA. For its part, China has signed and ratified the BA, and has also implemented domestic measures for the control of illicit e-waste imports (Basel Action Network, 2005) (United Nations Environment Programme, 2007). In addition to these steps, it has commenced development of its own standardized and state-sanctioned e-waste processing facilities. However, as the efforts of BAN indicate, these measures are slow to take root, and thus far appear to have many holes. Perhaps of greater concern with respect to China, and Asia in general, is that amidst the great disparities of wealth, the number of people occupying the affluent fraction of society is growing, as is consumption of consumer electronics. Given the size of the Chinese population, domestic ewaste management, along with so many matters, will be an issue of significant proportion. Much will rest on Chinese policy, for it will be in a position, as will other developing nations, to repeat the environmental errors of the west (in this case export or locally dump its domestic waste) or to develop the capacity to locally process its domestic waste and simultaneously rehabilitate contaminated sites.

\subsection{The United States}

Many eyes remain on the US with regard to electronic waste. There is, however, an interesting relationship between the US and both South Asia and East Asia. The raw materials that are 
refined into pure commodities used in the manufacture of electronic components are found in many parts of the world and are concentrated and shipped in large proportion to South Asia and East Asia for manufacture and assembly, often into the final product. From there, a significant proportion is shipped to western markets for consumption, which have traditionally been the home of most of the world's disposable income. The west has also been the home to the companies that have designed, managed the manufacture of, and marketed the products that have commanded the attention of the west's disposable income. Thus it is an interesting loop of material flow that sees products branded by companies headquartered mostly in the US return to places like China and India in the last leg of their product cycle. The US is home to companies such as IBM, HP-Compaq, and Dell and, on a per capita basis, it has been the most welcome home to computers. For at least a couple of significant reasons then, the e-waste management policies of the US are of great significance globally. The US government, consistent with its policies in a number of domestic concerns, has allowed market forces to rule the day in the ewaste arena with what appears to be mixed success for e-waste management. With some delay, the large computer brands have stepped in with various domestic initiatives. HP is offering recycling on a user pay basis, user must also cover the cost of shipping (Hewlett-Packard Development Company, L.P., 2007). Dell is offering free recycling of Dell branded products, while user are required to transport materials (Dell Inc, Dell Product Recycling, 2007). Apple offers a recycling system in which the transport is paid for by the user, and the recycling is covered by Apple Inc. (Metech-Arm, 2007). Just as European policy has had implications for multinational firms (and perhaps helped to usher in these US corporate initiatives), the absence of policy on this front in the US or, rather, the policy of allowing the market free reign, has given US firms the opportunity to respond slowly and with varied approaches, with user fees falling on 
different shoulders in different proportions depending on the firm. It is interesting, if also painful, to observe the ways in which unregulated competition in the provision of public goods, such as environmental protection, plays out. The potential for free riding is significant, there are no requirements for results or suggested methods of measuring them, and the mandate for the supply of service, as well as demand, is entirely voluntary, as the laissez-faire policy definition would have it. It is not difficult to make a reasonable indictment of these laissez-faire environmental policies where the provision of environmental goods is but another arena for competition in which firms can differentiate themselves without a relevant floor or ceiling for standards. This approach does not prevent, but may in fact lead to, disparities in environmental wealth on a local, regional, national, and international scale. It stands to reason that it has been the free market's lack of environmental compass and awareness that has put us in the current predicament with respect to e-waste; it should hardly be relied on for salvation. The inclination of the US firms which have undertaken voluntary recycling programs has been to shred equipment using capital-heavy machinery, and to recycle the metals and other materials. While this addresses some of the concerns of materials contaminating dumping grounds, it does not address the investment of energy that shredding requires, in addition to the material requirement of such capital and the surrounding plant. This approach disregards the energy and materials used to manufacture products in the first place. In essence, it is a regressive process, committing us (as a society) to repeat many of the manufacturing processes and energy commitments that were engaged by the products that are so soon considered waste. It is expected that these policy omissions will be left to subsequent generations to grapple with, and will prove to be the more substantial environmental challenges of the day. 


\subsection{Ontario, Canada}

In Ontario, Canada, the e-waste policy environment is a hybrid of the highly prescriptive style of the EU, and the hands-off approach emerging in the US. Emerging regulations in Ontario suggest that the mandatory acceptance by manufacturers of electronics returned for recycling will ensure high recycling or diversion rates. The implementation of this policy in Ontario is a response to a number of factors including Canada's ratification of the Basel Accord, the absence of federal domestic policy on the matter, inaction on the part of manufacturers, diminishing access to landfills, an increase in the popularity of the diversion of waste through recycling, and a recognition of increasing amounts of (and commensurate risks associated with) e-waste.

The design of e-waste management policies in Ontario began with designation of e-waste as a stream to be diverted from municipal residential garbage collection whose destination is a landfill. With that step came instructions from the Ministry of the Environment (MOE) to Waste Diversion Ontario (WDO). WDO is a public organization whose purpose is to study and develop high-level management plans for the diversion of designated waste streams and to conduct studies of those waste streams and available disposal systems. In previous years, this organization has received similar directives for items such as tires and oil. (Waste Diversion Ontario, 2007) A number of studies and learning processes were initiated, such as the formation of various stakeholder committees including one of computer and IT manufacturers and one of ewaste processors. The committee of manufacturers is a proto-committee for what will eventually become an industry-funded organization (IFO) which, via provincially enforced responsibility, will fund and manage e-waste processing contracts within the scope of relevant provincial regulations. 
The committee of e-waste processors is made up of representatives from companies currently engaged in the processing of e-waste, with a number of notable and nearly categorical absences including organizations, for-profit or otherwise, that champion reuse. It is expected that some of the e-waste processors constituting the committee will be contracted by the IFO to handle provincially designated e-waste. While much of the form and bureaucracy of the expectant ewaste management system has been discussed, nothing beyond the need for targets for reuse and recycling has been specifically set. Reuse in general has received few specific mentions, and certainly fewer where concrete objectives and processes were discussed.

Another group, a lobbyist organization that is funded by and representative of many of the protoIFO members' views, is Electronic Product Stewardship Canada (EPSC). This group has moved quite decisively in developing its own standards of e-waste processing for Canada and has received some official acceptance in a number of provinces. However, strikingly absent from their standards is any reference to reuse (EPSC, 2006). Just as the MOE, via WDO, was to delegate regulated responsibility for e-waste to the private sector (to manufacturers, for example), the manufacturers, via the EPSC, seem to be preempting this simply by beating the province to the punch. Given the province's inclination to delegate this to the private sector at arm's-length in the first place, it does not seem as an entirely unwelcome step. However, just as the absence of regulation in the US raises questions about the manner and quality of environmental protection, so does this evolution of policy in Ontario. While a democratic process does not by any means ensure an environmentally healthy regulatory result, and the absence of regulation does not protect the environment in any systematic way beyond voluntary 
measures, side-stepping a provincially initiated process by having the industry design its own process, seems to be fast-tracking the policy development process via a corporate policy development process. The cost of such a 'short cut' is the avoidance of considering more advanced environmental, social, and economic goals that are distinct from specific private financial interests considered by corporations. Ultimately in Ontario, and perhaps in many other parts of Canada, these corporate policies may eventually become state-sanctioned policies, the downside of which is that, like a company's internal policies, they more so protect the interests of the very few at the cost of lost opportunities for public goods and the wider swaths of society that those goods would serve. 


\section{CHAPTER 5: PROPOSED SUSTAINABLE E-WASTE MANAGEMENT SYSTEM (SEMS)}

The Sustainable E-Waste Management System (SEMS) is a response to an analysis of the observations made in the previous chapters; it is a response to the environmental harm and lost resources that result from e-waste being managed in an ad hoc manner. That being said, the SEMS has evolved chiefly in the living laboratory of Computation and, like any technology, technique, or management system, it has undergone and continues to undergo refinements, both with regard to its operational practices and with respect to the way in which objectives are conceptualized and communicated.

The focus of the SEMS is the processing of e-waste into reuse and recycling streams. Surrounding the SEMS process are the marketing efforts which drive material collection, and later resale, and the smelting and refining processes that take place after the SEMS. Both of these pre- and post-SEMS processes are key to the proper functioning of an organization which espouses the SEMS as its internal process. That being said, marketing and metallurgy are wellestablished and well-documented fields which will not be addressed here in any great detail. The emphasis of this chapter is confined to the period beginning with the entrance of the equipment into the facility of an e-waste processor and ending when the equipment is ready to be shredded or melted.

What differentiates the SEMS from Computation's functioning Environmental Management System (EMS) is that the SEMS, like any plan or idea, leaps ahead of what is currently practiced to suggest a direction for future improvement. It also differs in that it is significantly removed from client demands, as it is buffered from some of the parameters which confine the functioning 
of market-based solutions, allowing the SEMS to focus on best practices. The SEMS has two major substantive components: its governing principles and its operating system. Throughout the discussion of these components, examples from Computation's project base will be inserted for clarity and realism.

\subsection{SEMS: Governing Principles}

The SEMS was developed in the interest of taking the problem of e-waste and converting it into an opportunity. In other words, the objectives of the SEMS are nothing short of eliminating the concept of waste from the lexicon. William McDonough, the architect, author, and green designer, often suggests thinking that "waste equals food" for some other process (McDonough and Braungart, 2002). As with many management models, common sense underlies this approach: one person's garbage is another's gold. As we now know, this statement can be taken quite literally with regard to electronic and information technology hardware. From this seminal and overarching principle of reconceptualizing waste, which in fact results in a complete negation or reversal of its meaning, a number of secondary objectives naturally follow from and are satisfied by the achievement of the first objective. These secondary objectives include the following:

- diminish the "digital divide,"

- reduce the demand for raw materials and their associated environmental damages,

- reduce the demand for new electronic products and their associated resource consumption,

- eliminate the demand for landfill space required for e-waste,

- eliminate the soil and water pollution resulting from uncontrolled disposal of e- 
waste,

- increase the demand for research and development of more eco-effective and ecoefficient solutions such as the SEMS and the recycling and reuse of technologies, and

- increase the proportion of resources applied to the upcycling of material and equipment, rather than the downcycling common in conventional waste treatments.

While it may be held, generally, that the elimination of physical waste is an admirable goal, many readers may find that the secondary objectives listed above are more desirable than the primary goal. It must be responded that this reaction is a product of both environmental populism and the historical evolution of these secondary issues and, while their importance is not to be underestimated, their complete existential dependence on the generation of e-waste, and its direct link to consumption, is quite obvious in this context. From an environmental management perspective, where the goal is to reduce or eliminate several symptoms with a minimal investment of resources, a single solution for several problems may in fact be a kind of holy grail or Gordian Knot to be cut, and not painstakingly untied. Analysis of the damages caused by and the lost opportunities associated with e-waste all lead back to one common flaw: a mis-allocation of a post-consumer resource base to the category of waste. The term 'e-waste' is thus a kind of oxymoron or misnomer. In this mis-allocation, e-waste has much in common with other forms of physical waste and energy waste and, in its most general form, the notion of disorder or entropy. It is altogether too easy to become overwhelmed by the dramatically diminished value of a resource and to consider it waste, leading to a certain connotation, denotation, and expected treatment. Eliminating the concept of e-waste the SEMS requires a manager to consider the real 
residual value remaining in a body of equipment in addition to its potentially harmful effects; this means considering the utility to themselves as well as to others, or the total value. This method of consideration, along with the proper training and communication, will invariably lead to the recognition that e-waste does contain residual value, although the term 'waste' may remain with us for some time. A key tenet of the SEMS is that value should be maximally preserved through proper and careful handling of e-waste at all points in the supply, consumption, and disposal chains. (This will be discussed in greater detail as it applies to the operational treatment of e-waste.) The value of e-waste is preserved not only in the direct handling and treatment of equipment, but also in the design of products and the manner in which resources like e-waste are concentrated. For example, dispersed e-waste is less readily reclaimed in any valuable way.

The secondary objectives discussed above are then further translated into operating principles of the SEMS. These principles are necessary in order for a manager to be prepared to take concrete and tangible action on the matter.

While constructing this management system, it was of considerable value to consider why objectives fell into such a hierarchy. The two layers of objectives demonstrate a deductive logic from the grand over-arching theme of e-waste elimination towards tenets less broad in their scope. The elimination of waste in general is accepted as a truism; however, to develop a more specific understanding of the value in eliminating a particular kind of waste, one must consider the persistence of resources and material in more granular categories and how those categories can be manipulated to achieve the most desirable results. It is at this juncture that we must define a path to recover the maximum value out of produced materials for the minimum of 
environmental and other resources. In other words, it is here where the translation of the SEMS' higher principles into practical processes is aimed at realizing the greatest utility from e-waste while simultaneously creating barriers to the realization of its hazardous potential. To achieve this it is not sufficient to simply mimic the imperatives of traditional business and economics; it is these imperatives, detailed to some extent in the first chapter, that are responsible for bringing us to the current juncture.

While the objectives of the SEMS were born of the externalities of the IT industry, it is important to recognize that the logic of the e-waste processing industry encouraged by the SEMS must be very different than the industry which gave rise to it. While the IT industry is driven by the primary objective of maximizing economic throughput measured by the amount of equipment sales in dollar terms, and has traditionally dealt with waste in the least costly manner, the objectives of the SEMS include environmental preservation and social redistribution. In contrast to that of major IT equipment manufacturers, the goal of the SEMS is to close the material loop rather than to maximize volume.

Any principle or action should be directed towards yielding multiple types of benefits; this ensures that greater value is achieved and diminishes the possibility of externalities (if for no other reason than having considered multiple dimensions of value). While this may not be the picture of rational tidiness that many readers might hope for, it does reflect the complex interdependence of the reality in which we live. Specifically, this interdependence exists between the pillars of human ecology: the biophysical environment, society, and the economy. The recognition of the need to act on that interdependence in the interest of maintaining desirable 
balances (and of preventing the collapse of any one element) has been most thoroughly discussed, as relevant to this study, by the school of thought described as 'green business'. As the title suggests, societal considerations continue to play second fiddle to the importance of the economy and the biophysical environment. Green business is most succinctly described in the texts of authors like John Elkington, whose book Cannibals with Forks makes the case that, given the relative decline of the power of governments and the rise of corporate power, the resources that were part and parcel of this shift in power came with a commensurate social responsibility (admittedly this a soft and not a legal obligation) to manage more than the financial bottom line (Elkington, 1998). What Elkington distills for corporate executives is a revised operating and management system that is based on triple bottom line accounting using economic, social and environmental accounts. While any business manager can tailor this operating system to their taste and particular scenario, the general considerations hold firm across many types of business; that is, there is always value beyond the financial bottom line. Elkington's system recognizes that not accounting for this value, or not paying enough attention to it, will result in mismanagement of all that is unaccounted for. The model perhaps anticipates a time when values directly associated with environmental and societal factors will be incorporated into market mechanisms such as ethical investing and ethical consumerism. It is, therefore, strategically foresightful for managers to align their business with the shifting poles as change takes place. The first step is to recognize these new domains of value and identify whether the benefits relating to them fall to shareholders in the firm or to stakeholders outside of it, and also to identify whether there are trade-offs between the three pillars with respect to any potential business action. It is traditionally assumed that the financial bottom line remains the one that makes a business tick and provides for such basic items as the heating and cooling of 
facilities, but Elkington's model opens up a number of extra dimensions that give managers a 3D view of the landscape of options. For example, if we consider the hypothetical scenario of several financially equal options, what better way is there to differentiate among them than by considering their social and environmental outputs? This may mean choosing the best among bad options to minimize harm, but in its most general form it certainly means choosing the one with the largest net benefits. While monetized values are easy to compare, environmental and social concerns often prove to be more difficult. There is, however, good cause for businesses to derive a means by which to put a value on such factors as the alienation of the public, resulting in eroding the potential and existing client bases, or damage to the environment by diminishing a potential resource and perhaps incurring future remediation-related liabilities. The attempt to balance these pillars and to recognize to whom the added benefits are accrued (the business stakeholders or society in general) becomes a creative playing field, perhaps one that is more transparent and open to outside scrutiny.

The multiple layers of the SEMS' principles and objectives include the value of the environment and society, as well as the economy, and have given rise to an operating model that is consistent with the core elements of green business. The SEMS' framework centres on the delivery of two key environmental goods: resource recovery and the prevention of harm. Within its method of doing so; the SEMS has included a means for socially redistributing technology. It is these environmental and social outputs that are at the heart of businesses that follow the SEMS' economic and business processes. In essence, these two outputs are also economic outputs and, while the cost of generating such outcomes is easily measured, the inherent value of the outcomes is not so. Just how the SEMS generates these outcomes is the topic of the next section. 


\subsection{SEMS: Operating Procedures}

While the governing principles discussed above are general and inherently open to interpretation, the SEMS operating procedures are much more specific; however, the internal nonenvironmental standards that are applied in various product categories are known to necessarily vary with time, and are certainly open to adjustment in order to accommodate the varying scenarios surrounding their applications. Apart from this variability, the question of organizational scale is a relevant factor when defining the limits of operational procedures, but not when discussing governing principles. Our considerations here will take us from the IT consumer's door upon the disposal of the equipment through the SEMS process, to the second owner or raw material recycler; essentially, from grave-to-cradle.

The two main streams of material management are refurbishing and conventional recycling. It should be noted that specific old models of equipment have seen significant growth in their antique value in recent years, either for collectors or as use for props on movie sets; however, the low volume and temporary nature of these uses is no more than a passing relevance here. Generally, determining what will be reused or considered for refurbishing is a synthesis of various types of market demand. It involves determining what can be used in existing personal, professional, and academic environments, what will command a commercially viable price, and what equipment meets a minimum standard of performance when compared against its original out-of-the-box performance. The market for recycled raw materials commands higher rates for more pure materials; thus it has provided encouragement for more rather than less sorting of materials into distinct types. The process for each type of material will be discussed below. 
Each of these broad streams relates to the environment in its own way. Following performance testing and warranty certification, equipment destined for reuse in markets local to the origin of the waste is sold at the highest market-clearing price and, as a result, does much to ensure that the equipment will be used for its original technological purpose, as this price always exceeds the raw material value of a product. This is one instance in which the price conveys a significant amount of information regarding a product's intended usage.

In Computation's history, all equipment sold for reuse has been sold via its retail outlets in Toronto and Montreal, via eBAY, or has been sold wholesale to local distributors of used computer equipment. As the products will be reused, their working life is extended by a minimum of the 90-day warranty period with which they are sold (common warranty lengths for used electronic equipment are 30 and 90 days). The actual extension of the equipment's working life is much longer given the near absence of negative feedback, which happens with less than $1 \%$ of working goods sold by Computation (see seller profile for Computation Services in Appendix 3), the significant amount of repeat business, and amount of customer-referred business. It should also be noted that consumers of the second-hand markets can be quite frugal and at ease when conveying their needs and expectations of used products; this is not surprising as many are do-it-yourself types or experienced bargain hunters, and the lack of negative feedback is thus a significantly meaningful indicator.

While there is greater room for folly in an unregulated industry, if the price of a technological product exceeds the worth of its material components, it can be reasonably expected that the 
equipment will be used rather than carelessly stripped of its valuable raw materials. That being said, this is merely a rational tendency, and not an assured end. If products are sold for their commodity value at a price lower than that at which a working unit could clear the market, especially in large quantities, usually defined as units of shipping containers (20 or 40 feet in length), then the end use is, without a doubt, some form of resource recovery. In these situations, the end client must be audited to ensure that materials are not dumped or disposed of in some other uncontrolled manner. There are also occasions where quantities of equipment, both large and small, are sold without warranty in 'as-is' condition with the intention of refurbishing the equipment (usually in regions where labour is less costly) or using it to recover spare parts. Again, for some reasonable assurance that equipment sold in such a way is handled in an environmentally responsible manner, the end market must be audited. Prior to such a sale, a number of preliminary steps must be taken, beginning with initial material triage.

The core of the operating procedures of the SEMS is the initial material triage that separates a quantity of equipment into two broad categories: (1) equipment with general reuse or refurbishing potential, and (2) equipment whose whole body or majority of parts will be recycled into raw material form. Within these two categories, there are several types of computer-related e-waste, as indicated below:
A. monitors (CRT \& LCD),
B. desktop and tower computers,
C. printers, scanners, and multi-function,
D. laptops, 

E. peripherals and accessories, and
F. cables.

\subsubsection{Reuse and Refurbishing}

Each category of equipment has specific criteria against which the reuse or refurbishing potential of its constituents can be determined, sometimes with a simple yes or no answer, but often requiring further investigation. It should be kept in mind that the origin of a batch of IT equipment often provides considerable clues or contextual information regarding the residual value of materials that are consistent across the entire batch. Corporations tend to have a higher concentration of economic wealth and level of income. As a result, their time would be better spent pursuing their specialization rather than dismantling batches of IT equipment, which makes an easy case for the outsourcing of such e-waste management processes. Equipment recovered from such places will often be newer, more likely to be in working condition, and just plain better. Quantities of household equipment, however, will be smaller, denying the possibility of identifying within-household patterns and, like corporations, their quality will vary with demographic factors-primarily affluence. In the case of wealthier entitites, be they large corporations or small families, the recycling intake process can provide the SEMS recycler with much useful information regarding the condition of the goods. This information, whether simply observed or actively solicited from the recycling client, can and should be taken into consideration when testing the equipment; in fact, this is a necessary step in the commercial recycling process as the presence or relative absence of residual value will often help to determine the monetary charges for e-waste management services. In addition to demographic factors that provide clues to equipment evaluation, signs of water damage, fire, and corrosion are 
strong indicators that a system or significant parts should be dismissed from reuse potential. The following sections describe the assessments of reuse potential to be made in each category.

\subsubsection{MONITORS}

Received monitors first have LCDs removed, leaving only the stock of CRTs; the latter are by far the current majority in the e-waste stream. All LCDs whose structures are intact (no noticeable cracks, exposed wires, or significant blemishes on the screen) are tested and considered for repair as they have a local resale value here in Toronto of $\$ 80$ to $\$ 175$ (15" to 17'), depending on size (participant observation, 2007). Performance testing considers the brightness of the screen, the ability to adjust the brightness, the ability to have the picture reach the edges of the screen, and the clarity of picture. In all respects the monitor should be pleasing to the eye, while minor blemishes such as the absence of several pixels, or 1 to $2 \mathrm{~cm}$ discolourations will be noted and conveyed to potential users, as these are acceptable for a number of applications. Once repaired, LCDs are left on for several hours to ensure reliability.

All cosmetically disfigured CRT monitors of any size (cracked exterior plastic shells, extremely discoloured shells, major scratches on screens, screens with visible burn-in of images, or exposed wires) are removed and destined for material recycling. Similarly, dumb terminals, even if suspected to be in working condition, are handled in this manner as they are usually very old, with the exception of more modern variants made by WYSE and Sun Microsystems. The remaining stock consists of PC \& Apple monitors in a cosmetic condition suitable for reuse. (Apple has traditionally held approximately a single digit percentage of the PC market, and this proportion is similarly maintained in e-waste streams; however, it appears that Apple hardware 
retains value and the attachment of its owner longer so that it takes up even less of the recycling stream) (Forbes.com Inc., 2005). Beginning with larger units of 17 or more inches (measured from diagonally opposing corners of the screen) that have significantly greater residual value, if still working, each unit is tested for 5 to 10 minutes using the same criteria described above for LCDs. If these tests are passed, the unit is then considered part of marketable inventory. If not, the unit is destined for disassembly and recycling. There are relatively rare cases where a 19 inch or larger monitor simply suffers from the need for a slight adjustment. Certain models have adjusting screws inside the case at the rear and, for a sufficiently talented technician, this can prove a worthwhile exercise. For smaller monitors of less than 17 inches, similar tests are conducted but with less tolerance for imperfection, especially at the cosmetic level, as these units sell for $\$ 5$ to $\$ 10$, so there is little value to be recovered in processing them as working goods if they have obvious blemishes.

\subsubsection{DESKTOP AND TOWER COMPUTERS}

Like the monitors above, this category of equipment undergoes successive layers of processing to expose the stock which has recoverable reuse potential. Initial visual inspection of the equipment allows for the separation of complete systems from those that have already been partially disassembled prior to receipt. Partial systems, as well as any complete systems based on Intel Pentium II or older processor, are destined for disassembly. For Apple technology, the current cut-off is units with less than a G3 processor; for Sun Microsystems it is units older than the Ultra 10 model. In the process of disassembly, all major components of the computer are to be separated from each other and from the chassis in which they were mounted, leaving behind individual cases, floppy drives, optical drives (for CD/DVD), hard drives, RAM, CPU, heat sink 
and fan, motherboard, power supply, screws, cables, and CMOS battery. Any parts which can contribute to the refurbishing of more current computer models, or ones missing any of these specific parts, are tested and reused in this manner. Generally, only Pentium III processors or higher are retained, as are RAM of 64/128MB or higher, hard drives of $6 \mathrm{~GB}$ or larger, ATX power supplies of $300 \mathrm{~W}$ or larger, DVDs, CD-ROMs of $48 \mathrm{X}$ or higher, floppies, and cables as needed. Any remaining parts are collected until sufficient quantities have been accumulated for delivery to smelters or refiners. Hard drives destined for recycling are first punctured with a drill through the disk's platter. A description of parts testing and reuse will be included in the discussion of system refurbishing.

Systems that are not disassembled are examined more closely for signs of trauma or for the scents associated with parts having burned, and the motherboard is examined for bloated capacitors, which would not be immediately evident in a computer's performance. At the same time, all desired internal connections are checked. Barring any reasons for concern in these areas, the computer is connected to a known working monitor, keyboard, mouse, and power outlet and is turned on. Following proper configuration of the BIOS if necessary, the computer is rebooted, set to boot from floppy or CD, and software is run to first confirm the health of the hard drive, and then (if passed) to erase any existing data by passing over the disk three times and writing over each bit with a random value on every pass. If the drive proves faulty, it is drilled and destined for material recycling. Following this step, which can take 20 minutes for $6 \mathrm{~GB}$ (time requirements growing linearly with increases in drive size), the various basic functions are tested including the keyboard, mouse, floppy drive, CD-ROM, printer, USB ports, monitor, sound, RAM, CPU, power supply, fans, and network connectivity. This requires approximately 30 
minutes. Should any of these parts fail, they are added to the collection of parts separated from disassembled units destined for recycling. Before spare parts can be utilized in the testing process, they must themselves be tested. Testing of parts should take place in computer systems that have already been fully refurbished and are certified as working so that failure of a part will not regularly call into question the functionality of the whole system. Parts that have operated normally in such an environment can be then considered tested and suitable for use as spares or in the refurbishing process. Once all the basic functions of a computer have been confirmed, the computer's configuration is noted in the inventory system and on the computer itself, and it is considered refurbished. If the computer shows faults which cannot be isolated to a basic and easily replaced part (for example, if the motherboard is faulty) the system is destined for disassembly.

\subsubsection{PRINTERS, SCANNERS, AND MULTI-FUNCTION}

While computers and monitors are somewhat simple in their distinctions among various calibres of units, printers and similar equipment are much more complicated. There are three major categories of printer: laser, inkjet, and dot matrix. (While there are also thermal, wax, and pen plotters they represent a small fraction of the total.) There are also scanners and inkjet or laser technology-based devises that perform one or a combination of printing, scanning, copying and faxing. Adding to this complexity is whether or not a device operates in monochrome or in colour. Finally, unlike the other categories where brand either does not play an operational role in refurbishing (as with monitors) or, if it does, it is sufficiently popular in terms of market demand and available spare parts, the brand of a printer, in addition to its modernity, is important. Printers must be regularly refuelled with ink for inkjets and toner for lasers, but it is 
not a simple recharging process where one refills a tank as with a car. A complicated cartridge with a limited life span must also be replaced, and the availability and cost of these cartridges does much to support the market for both new and used printers. Few models of printer share the same model of cartridge.

It should be noted that these cartridges can be refilled or refurbished as well, but not all models receive this sort of secondary market demand and, if they do, the duration of supply varies according to the popularity of the printer.

As a result of these complexities and the fickleness of the market (the printer market is mostly a market for the delivery of ink; it is considered a razor blade strategy where the handle is sold cheaply but the replacement razors are not) it is important to pick popular and sufficiently current models for the refurbishing process. While the need for focus is important, there are a number of exceptions of niche models with specific purposes that command excellent value even in their advanced years. The most common brands of laser printers are Hewlett Packard (HP) and Lexmark and, again, there is a close relationship between quantity sold and quantity to be disposed of. In current market conditions, models beginning with the HP 4 or later and Lexmark Optra S series or later retain sufficient residual value to be reused (these are 'work-horse' commercial printers). Though they are not of sufficient value to justify employing heroic measures in their repair, basic cleaning and swapping of toner, fusers, trays, and other easy to replace parts is economical. As with PCs, the parts from partial or faulty printers are used in the refurbishing of units in near-working condition. Successful printer refurbishing is evidenced by clean, clear, and sufficiently dark prints with an absence of horizontal and vertical stripes of off- 
shading, as well as a mechanical system which produces a smooth flow of uncrumpled paper and a relative lack of paper jams. Any displays or control panels should be clearly visible, and the latter should be responsive to the touch. Printers with model numbers like those identified above or newer quite regularly reach 300,000 to 400,000 printed pages in good health, while these often arrive at Computation facilities for recycling having reached only 50,000 to 150,000 printed pages. The striking parallel with automobiles is that both the metric and precise numbers are similar in determining the degree to which a device was used. It should be added that colour printers are even more valuable than monochrome printers, while the cost of a complete set of toners for these colour printers is approximately four times higher than that of monochrome devices; thus, reuse in this category is engaged in much more cautiously.

The most common brands of inkjet printers, in declining order of popularity are HP, Epson and Canon. Here, as with smaller sized monitors, there is a smaller margin to be gained for wasted time in refurbishing; it appears best to allow precise market demand to drive refurbishing. That is, refurbishing should proceed on a by-request basis, which is feasible for this category as the units themselves are quite small and require little storage space. Where there is no demand for particular units, they should be disassembled in preparation for material recycling. Ultimately, most equipment in the inkjet category (colour or otherwise), with the exception of multi-function units which are relatively newer, will be destined for recycling. Essentially, the fact that original equipment manufacturer (OEM) replacement ink costs an amount similar to that of a new printer drives buyers to purchase new printers. With regard to refurbishers, there is significant challenge and demand for resources required to keep a ready inventory of all the desirable types of ink cartridge and, as a result, refilling services are as common as stores providing pre-refilled ink 
cartridges.

Conversely, scanners represent a category in decline due to the pairing of scanning technology with that of fax, copier, and multifunction devices. Given the economy afforded by multifunction devices, as well as the convenience and the relatively low cost, consumer-grade, single-purpose scanners, unlike other categories of IT equipment, have reached a state of obsolescence more convincingly. Scanners should be slated for reuse on a by-request basis and excess stock should be slated for recycling.

Multi-function units in the e-waste stream are typically made by HP and Lexmark. While new models may exist which will eventually stimulate changes in this process, for the time being Lexmark is recognized as only having ink-based devices in this category, while HP has both ink and laser units. Given the rationale described above, the desirability of refurbishing ink-based multi-unction units is somewhat limited. For laser units, however, demand is quite strong, as the product is very durable and refurbished monochrome toner can be readily found. HP models beginning with the 3000 series are suitable for basic refurbishing efforts.

\subsubsection{LAPTOPS :}

Laptops are a special category of device. Their popularity in the market continues to increase, though they have traditionally been the minority in total PC sales (LeClaire, 2002). While their cost continues to decrease, they remain near or above the $\$ 1,000$ mark, though basic units are beginning to appear for around $\$ 600$ from the major manufacturers. Older units cost much more when they were purchased. As a result, laptops retain more residual value at their end-of-life 
than desktops, both in absolute and relative terms, and laptop parts are among the most valuable in the IT repair industry. The portability of laptops exposes them to much more motion than desktops (resulting in more physical shocks) and makes them more fragile. As a consequence of their value and exposure, laptops require repair more frequently than their relative share of the market would suggest; this is also partly due to the high cost of replacement which often exceeds the cost of repair enough to steer consumers in the latter direction. These characteristics have a number of implications for reuse. Laptops with Pentium II processors retain some market appeal, essentially satiating the demand for portable typewriters that are light and do not require paper. Thus, Pentium II and later laptops are processed like desktops when assessing them for reuse. If they fail these tests for reuse, their compactness demands much less in terms of storage and the value of their parts highly recommends that they be dismantled and that the known faulty parts be recycled, while the remaining parts be retained as replacements. One of the more common reasons for which a laptop is rendered useless, with respect to the condition of its hardware, is a cracked screen. Given that there are many other, non screen-related reasons for which a laptop becomes unusable such as damage from spills of liquid, retaining working screens for replacement parts is a wise idea. Certainly, there are numerous other useful parts, especially given that unlike the generic construction of desktops in which most parts can be readily traded between PCs of different brands but of the same calibre, laptops are generally proprietary in their design. Whether it be between brands such as IBM, Dell, or HP or between model lines such as Latitude, Inspiron, Pavilion, or Toughbook, with the exception of hard drives and external devices, the ability to swap laptop parts is the exception and not the rule. This design characteristic created a kind monopoly over spare parts for the OEMs, with commensurately higher prices than might be expected, especially in the early days of computing 
when there were simply fewer units sold, and even fewer second-hand units being supplied. In current second-hand markets, these design characteristics maintain higher prices for laptop replacement parts, though they are still much lower than replacement parts from the OEMs. The major components which, if working, should be retained for reuse are floppy drives, CD-ROMs, hard-drives, screens and LCDs, keyboards, RAM, motherboards, chassis, batteries, power supplies, and even miscellaneous bits of plastic if their use is known.

\subsubsection{PERIPHERALS AND ACCESSORIES}

While this is certainly a broad category in the ever-expanding IT industry, some devices appear with far greater regularity than others: namely, keyboards, mice, scanners, and external drive cases. As has been suggested with monitors, even though a large number of keyboards are disposed of each year, it has been inferred from the frequency with which consumers decline the free keyboard and mouse that accompany the used computers sold at Computation that these devices are often retained by their users through multiple PC changes. As they are the connection between user and computer, they may retain a more personal value than the other more removed devices. Thus, a greater tendency of reuse or extended life is built into these devices, thereby diminishing the need for third party reuse, although we do recognize that each set of keyboard and mouse disposed of is likely to have been already replaced. Testing these devices is rather simple; each key on the keyboard must represent its likeness (including secondary symbols) on a screen when tapped and a mouse must accurately track the hand's motion when being moved and have responsive buttons. Failed devices, or those of lower value (newer units being preferred for reuse) whose second-hand supply grossly exceeds demand, should be channeled for recycling. 
External drive cases and other devices of more minor importance (often single-purpose devices) that do not lend themselves to repair are also not the object of great demand. The resulting treatment has been to reuse them on a by-request basis and, otherwise, to strip them of any useful components, such as cables, and forward them for material recycling.

\subsubsection{CABLES}

Cables are a regular component of the IT recycling stream. Whether they be internal or external cables, they are always present. To an even greater extent than keyboards, external cables are overproduced. Take power cables, for example. Each computer system consists of a monitor, a PC, a keyboard, and a mouse, and requires two power cables: one each for the monitor and PC. Add an additional power cable for each printer. These power cables are highly robust and are rarely damaged to the point of being unsafe or not useful. The lifespan of these cables could quite easily be in the tens of years, if not semi-centennial, yet each new computer system comes with two. The longevity of this item is attested to by the frequency with which their free provision is rejected at the time of computer purchase, as well as by the observation that electrical cabling is treated by consumers, residents, and office employees more as part of the infrastructure of a place than as part of the device. The devices come and go, but the power cord stays. This logic does not apply to internal cables, as most do not see the light of day once deployed. External cables have not undergone much change in the history of computing. The power cable is still in its original version and, while USB printer cables are becoming more common, the parallel cable (the original printer cable) remains prevalent. Given their pattern of 'built-in' reuse, these two types of external cable have diminished third-party reuse potential, but 
some quantities should be retained for this purpose, while the remainder are recycled. Internal cables have limited reuse potential as cables rarely malfunction. Also, a number of internal cables have undergone revisions to the point where older models of cable receive little demand. Again, stock should be retained, but the majority recycled.

\subsubsection{Materials Recycling}

Up to this point, this report has not described the process by which equipment with reuse potential is segregated from that without it, therefore destined for material recycling, as well as how units, following testing, are disqualified from the reuse stream of materials and are merged with the recycling stream. It is at this point where the limit of the reuse system can be identified. Once equipment is in the recycling stream, a number of preparatory steps must be followed to prepare materials for a process of recycling which will downcycle them into a less valuable class of property: raw materials. The following types of activity differ considerably from those involved in refurbishing. The processes here are based on weights and volumes, rather than units of equipment. The skills involved are mechanical, and in some cases downstream e-waste processors (those focused on rendering equipment ready for material recycling) have opted for a capital-intensive treatment involving heavy machinery. This section will advocate and look more closely at pathways that take manual, labour-intensive material preparation as far as possible in the interest of fuller employment of staff and the less intense use of material resources such as those required by capital machinery. These preparatory steps essentially strive to reconsolidate the diverse materials present in IT equipment into groups of physically similar materials. In some cases, these processes of manual sorting are sufficient to isolate a single material type, or to isolate it to a point where the impurities will act only as fuel in the primary 
material's smelting and refining, thus aiding and not impeding the material recycling process (although it should be noted that the combustion of these impurities cannot proceed in an uncontrolled manner as it may generate hazardous pollutants) (C. Thomas, pers.comm., 2004).

In other cases, there is no avoiding the need for heavy machinery to sufficiently separate materials to achieve a reasonably efficient smelting and refining process. In this process, the material is chipped and ground into progressively smaller pieces until eventually it reaches a sand-like granularity. Along the way, the material is sorted by density and magnetism, these being the most efficient means of distinguishing between various material types (C. Thomas, pers.comm., 2004). Invariably, the application of heat is the final destination, as it allows for the materials to be reformed, both in purity and shape. Again, density plays a part; lighter materials will float to the top of a batch and, via skimming, greater purity of the primary material will be ensured. Other materials, such as organics, that are flammable at temperatures below the melting point of metals will be burned away, providing fuel for the smelting process. This process will continue, in many cases, until relatively pure fundamental elements such as aluminum, lead, and copper are attained; in other cases, the goal is to reform compounds such as steel and glass. Here, too, there are environmental impacts. They are not the same ones involved in primary material refining, but others introduced by the added chemical complexity of post-consumer materials such as the inclusion of poly-brominated-bromines (PBBs) as fire retardants in a variety of IT components. Smelters and refineries should be adequately equipped to handle the changes in their feedstock material, to ensure that no new environmental side effects are added by the implementation of this solution, and that known effects are not enhanced. 


\subsubsection{RECYCLING PREPARATIONS}

Recycling preparations begin where sorting, testing and refurbishing efforts end. Each category of materials with respect to refurbishing provides a starting point for the material recycling process, also known as downstream recycling as it is further from the point of disposal in terms of the number of processing steps already completed. Various factors will shift the boundaries that separate reuse, recycling preparation, and downstream recycling, including, but not limited to, changing material content and ease of disassembly. One of the key principles governing recycling preparation is that the value of commodity materials is governed by their purity; the greater the purity, the greater the economic worth due to the lower cost of refining. As with refurbishing, the processes of sorting, disassembly, and material separation add increasing value to electronic scrap materials. Several of the six reuse categories previously discussed have much in common from a material standpoint, while others are more unique. These sorting processes end where the capabilities of smelters and refineries are required, usually when the application of high heat, chemicals, and grinding are necessary.

\subsubsection{MONITORS}

Monitors have several major components, including the following:

- video cable,

- plastic shell,

- cathode ray tube (lead lined glass, and copper yoke),

- power and controller circuit board, and

- aluminum heat sink. 
To prepare a monitor for recycling, the external cable should be clipped from it and joined with the other cables to be recycled. The plastic shell of the monitor should be removed intact and bailed for delivery to plastics recyclers. Plastics of different types should be kept separate according to the requirements of the plastic recyclers that an organization partners with. Generally, more specific and granular separation of different plastics types leads to more efficient downstream processing. The cathode ray tube should be cracked by staff equipped with a proper respiratory apparatus and working under a fume hood, separating the predominately copper yoke from the lead-lined screen and funnel, the screen and funnel should also be separated. The glass from the screen and funnel should be stored separately as the amount of lead on these two types of glass differs, with the funnel always having the lower density of lead (participant observation, 2007). The circuit boards are considered to be low-density circuit boards and should be kept separate from other types of circuit boards found in desktop computers and laptops. This low-density rating refers primarily to the precious metal and copper content. Aluminum heat sinks (comprised of relatively pure aluminum) should be removed from the circuit boards and stored separately.

\subsubsection{DESKTOP AND TOWER COMPUTERS}

As listed in the description of reuse procedures in section 5.2.1.2, computers are made up of the following:

- cases

- floppy drives

- optical drive (CD/DVD)

- hard drive
- RAM

- $\mathrm{CPU}$

- heat sink and fan

- motherboard 
- cables

Cases are made of either steel or plastic, or a combination of the two. Once disassembly of a PC is complete, the plastic and steel parts of the case should be separated and all the remaining parts should be stored separately. As mentioned above, plastics of different types should be segregated as per the plastic recycler's requirements. Both plastic and steel should be separately compacted and bailed. In all cases, batteries should be removed from motherboards to avoid minor but damaging explosions in downstream recycling machinery. Motherboards, fingerboards, RAM, and CPUs are valued for their precious metals, copper, and aluminum content. Numerous health, safety, and environmental challenges arise in efforts to extract the small quantities of precious metals present in these devices. Methods used by downstream recyclers should be assessed against environmental, health, and safety standards when being considered for downstream processing. Where possible, fans should be removed from heat sinks to ensure the greatest purity of aluminum, and clean aluminum heat sinks should be stored separately from those which have attachments still affixed. The near purity of the clean aluminum provided by heat sinks and the effectiveness of mechanical processes in removing non-aluminum from those units with attachments does much to diminish the challenges of recycling this material type, as there are no materials except for aluminum present in the feedstock. The remaining material types should not be disassembled further (with the exception of cables being clipped from the power supply) because the rate at which equipment is processed is far too low to be cost effective, especially when judged against labour costs in developed countries and the value of the material (mostly steel) in the various drives. The remaining material will be mechanically ground and separated 
before being melted down.

\subsubsection{PRINTERS, SCANNERS AND MULTI-FUNCTION}

This category is particularly difficult to prepare for recycling for reasons similar to those guiding the reuse selection process in section 5.2.1.3. The degree of standardization present in this category of equipment is much less than is present among PCs or monitors. There is much less empty space within these products, and manufacturers have opted for very different designs not only from their competitors, but also among their own model lines. There is also a significant lack of modularity when compared with PCs or monitors; a large number of parts, a variety of different plastics and metals, and a considerable mix of plastic and metal parts present a number of hazards to the equipment that would be recycling plastics or, conversely, inefficiencies for the metal smelting or refining process. Essentially, this barrier to dismantling favours machine-based rather than manual recycling preparation (shredding) earlier in the downstream recycling process.

\subsubsection{LAPTOPS}

Laptops contain all of the same materials present in PCs, the major exceptions being the internal LCD (in lieu of a monitor), the battery, and the power supply with its AC/DC transformer. The compact nature of laptops means that each part is smaller and weighs less. Their more resilient value retention, and less extensive penetration of the market means that fewer laptops are seen by recyclers. In fact, observation of recyclers in the Toronto area suggests that current value retention in these devices remains so high that there is sufficient market demand to ensure that this category sees the highest rate of diversion through reuse. The implication here is that laptops 
do not currently make up a large fraction of the units destined for downstream recycling, and they do not represent a large mass per unit, which is both a blessing and a curse: they require greater effort to divert less waste or recover less matter. Aside from the major components listed above, the remaining components of the laptop are the chassis (equivalent to the case of a PC, but almost always entirely plastic), the motherboard (the CPU is typically permanently fixed to a laptop motherboard), the hard drive, the floppy drive, the CD-ROM, and the RAM. Batteries and power supplies (once the cables have been clipped from them) need to be recycled separately from the remaining materials due to the presence of relatively low quantities of potentially harmful substances such as lead, acids, nickel, and cadmium. The LCD contains a fluorescent tube backlight that contains trace amounts of mercury vapour and would ideally be recycled by a processor that can captures it. That being said, the quantity of vapour is negligible compared to that which goes uncaptured in the handling of conventional fluorescent tube lighting. The remaining parts can be stored with their desktop computing counterparts.

\subsubsection{PERIPHERALS AND ACCESSORIES}

The treatment of items in this category is similar to that discussed in section 5.2.1.5. Their lack of homogeneity and small size favours mechanical shredding and sorting. As with all other equipment, modular components should be removed and stored in containers holding similar components and should similarly be assessed first by material content, and then secondly by function. Any internal or external cables should also be removed and stored with other cables.

\subsubsection{CABLES}

While almost all cables include copper bearing, they are also insulated to varying extents; their 
ultimate destination is to recyclers of copper. The most popular means of recycling copperbearing cable is to use the insulator as a fuel in the smelting process, thereby subsidizing the heat needed to fuel the smelting process and eliminating the insulator. Concerns with this method are the harmful by-products caused by the combustion of the insulator materials, namely furans and dioxins (EPSC, 2006). Proper precautions must be taken by downstream recyclers and smelters to ensure that the creation of these harmful compounds is avoided or that, at the very least, they are not released into natural environments. This would prove exceedingly difficult as storage technologies are wrought with imperfections, and require a lasting commitment to properly maintain them. 


\section{CHAPTER 6: CONCLUSIONS AND FUTURE RESEARCH}

What is at stake here in this report's final analysis of the problem of e-waste, its expected solutions, and the solutions which would best serve sustainability is treating this issue in a business as usual approach. The result of doing so is to ensure that in large part the solution set adopted for e-waste will be generally like that of most other waste streams (though it may differ marginally), that is to say, materials will be packed off into a truck at the end of each day, hauled to soine distant (though perhaps within the generator's province) facility where the materials are shredded and or melted, but almost universally downgraded into a raw material form whose value per unit weight or volume is significantly less than that of the original product. The investment of resources in that original product - monetary, caloric, environmental "externalities," and social - have been quite literally obliterated and the obliteration process itself again required the investment of similar resources as the original product. While this process qualifies as recycling it too generates waste, and though it is better than landfilling products after a first pass, even a $90 \%$ efficient recycling process results in the original mass being wasted after 10 passes - it only delays the ubiquity of waste, it does not avoid it (Palmer, 2007). We must begin to play the end game now, we must work backwards from that state of affairs which we would like to avoid, and if we dare, also work backwards from that state of affairs which we would like to one day enjoy. Conventional recycling, while still a progressive step, is grossly insufficient. While some may exalt its improvement over direct landfilling (direct pollution/emission), to the planner it can only be seen as the devil in disguise. The energies which are being applied to turning the same tired old wheel which is recycling should increasingly turn to (indefinite) reuse, building to last, and green design. 
Reuse, our aversion to it or adoption of it, is driven by two broad factors: consumer behaviour, and the quality and by design useful life of the products we own. This assessment places the responsibility for reuse squarely on the shoulders of both the consumer and the producer. While it is safe to say that the producer is clearly the more powerful of the two actors in this equation, the consumer should not be quick to abdicate. The consumer need not be so fickle in following the latest technological fashions, so quick to discard the product which last week 'saved' them and this week troubled them so. The consumer should strive for greater independence from the producer and develop the capacity to maintain their equipment more effectively, either on their own, or in their community. These aspirations should be communicated to the producer, translated into a market signal which will reward the producer who responds to them with greater market share, and certainly increased loyalty - certainly a longsighted strategy which is not compatible with the relatively short tenure of corporate CEOs. The producer can relatively easily build more durable products, products free of hazardous substances, products which can be maintained/upgraded/kept current more readily.

The current approach for e-waste, as with so many product categories, lack innovation or the basis for any real change. By facilitating the existence of a class materials known and treated as waste, advocates of "waste management," and its sister "recycling" are perpetuating our disposable culture. So long as we are prepared to maintain an extensive collectiọn, transport, sorting, and processing structure to manage waste and recyclables participants in society will continue to create materials suitable for absorption by that structure with the abandon and thoughtlessness that they have. What is required is that not only the purchase price, but the 
matter, energy, and human and environmental resources (both positive and negative) that went into each product, regardless of how seemingly insignificant (clothespins, paperclips, keyboards, mice, pens, pencils) be preserved as much as possible at each step of its existence. As part of that preservation a craftsperson approach should be reverted to in many areas - this is not to fully discount the utility of mass production, but merely to confine it to a definite rather than ubiquitous existence - there should be greater production of heirlooms, elimination of toxic ingredients, and the implementation of modular designs which facilitate easy repair and upgrading.

Reuse as it is possible today with systems like SEMS is merely indicative of what could be done if we all decided to row together, it is a small piece of the puzzle at the end of the pipe, while it would find a significant place in an environmentally redesigned complete product life cycle management system. Designing heirlooms would be the key to a forward looking system, in the long run it would marginalize programs like SEMS which thrive only in an otherwise wasteful context. To summarize our limited ability to absorb physical waste on this planet, to invest energy and clean water in products and then discard the product, and our apparent need for things I find wise counsel in the words of a Moldovan friend: "We are not rich enough to buy cheap things" (V. Gritac, pers. comm., 2006). 


\section{APPENDIX 1 - Signatories to the Basel Accord}

\section{Countries}

Afghanistan, Albania, Algeria, Andorra, Antigua and Barbuda, Argentina, Armenia, Australia, Austria, Azerbaijan, Bahamas, Bahrain, Bangladesh, Barbados, Belarus, Belgium, Belize, Benin, Bhutan, Bolivia, Bosnia \& Herzegovina, Botswana, Brazil, Brunei Darussalam, Bulgaria, Burkina Faso, Burundi, Cambodia, Cameroon, Canada, Cape Verde, Chad, Central African Republic, Chile, China, Colombia, Comoros, Cook Islands, Costa Rica, Côte d'Ivoire, Croatia, Cuba, Cyprus, Czech Republic, Democratic Republic of Congo, Denmark, Djibouti, Dominica, Dominican Republic, Ecuador, Egypt, El Salvador, Equatorial Guinea, Eritrea, Estonia, Ethiopia, European Community, Finland, France, Gambia, Georgia, Germany, Ghana, Greece, Guatemala, Guinea, GuineaBissau, Guyana, Haiti, Honduras, Hungary, Iceland, India, Indonesia, Iran (Islamic Republic of), Ireland, Israel, Italy, Jamaica, Japan, Jordan, Kazakhstan, Kenya, Kiribati, Kuwait, Kyrgyzstan, Latvia, Lebanon, Lesotho, Liberia, Libyan Arab Jamahiriya, Liechtenstein, Lithuania, Luxembourg, Madagascar, Malawi, Malaysia, Maldives, Mali, Malta, Marshall Islands, Mauritania, Mauritius, Mexico, Micronesia (Federated States of), Monaco, Mongolia, Montenegro, Morocco, Mozambique, Namibia, Nauru, Nepal, Netherlands, New Zealand, Nicaragua, Niger, Nigeria, Norway, Oman, Pakistan, Panama, Papua New Guinea, Paraguay, Peru, Philippines, Poland, Portugal, Qatar, Republic of Korea, Republic of Moldova, Romania, Russian Federation, Rwanda, Saint Kitts and Nevis, Saint Lucia, Saint Vincent and the Grenadines, Samoa, Saudi Arabia, Senegal, Serbia, Seychelles, Singapore, Slovakia, Slovenia, South Africa, Spain, Sri Lanka, Sudan, Swaziland, Sweden, Switzerland, Syrian Arab Republic, Thailand, The former Yugoslav Republic of Macedonia, Togo, Trinidad and Tobago, Tunisia, Turkey, Turkmenistan, Uganda, Ukraine, United Arab Emirates, United Kingdom of Great Britain and Northern Ireland, United Republic of Tanzania, United States of America, Uruguay, Uzbekistan, Venezuela, Viet Nam, Yemen, and Zambia.

(United Nations Environment Programme, 2006) 


\section{APPENDIX 2 - Ratifiers of the Basel Accord}

63 Countries.

Antigua and Barbuda, Argentina, Australia, Austria, Bahamas, Bangladesh, Belgium, Brazil, Canada, Chile, China, Costa Rica, Côte d'Ivoire, Croatia, Cuba, Cyprus, Czech Republic, Denmark, Ecuador, Egypt, El Salvador, Estonia, European Community, Finland, France, Germany, Greece, Guatemala, Hungary, Iceland, India, Indonesia, Iran (Islamic Republic of), Ireland, Israel, Italy, Japan, Jordan, Kuwait, Latvia, Lebanon, Liechtenstein, Luxembourg, Malawi, Malaysia, Mauritius, Mexico, Namibia, Netherlands, New Zealand, Nigeria, Norway, Oman, Pakistan, Panama, Peru, Philippines, Poland, Portugal, Qatar, Republic of Korea, Romania, Russian Federation, Saint Lucia, Saudi Arabia, Senegal, Seychelles, Slovak Republic, Slovenia, South Africa, Spain, Sri Lanka, Sweden, Switzerland, Syrian Arab Republic, Trinidad and Tobago, Turkey, United Kingdom, United Republic of Tanzania, Uruguay, Viet Nam and Zambia.

(United Nations Environment Programme, 2006) 


\section{APPENDIX 3 - eBAY Feedback Profile: Computation Services}

C. ellay I cedluack Profile for computationservices. Windows Internet I xplorer

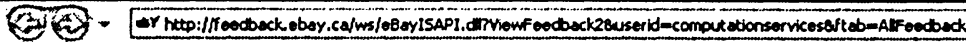

(t) $x-6$

Filo : Edik how Favarkes Toots Help

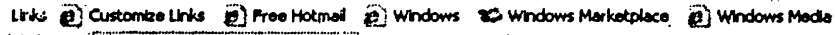

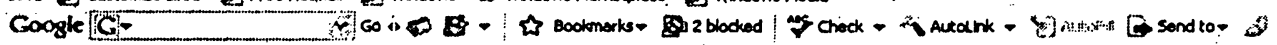

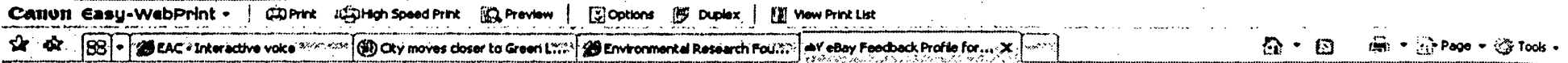
Hellol signin or Legister

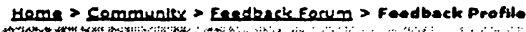

Feedback Profile

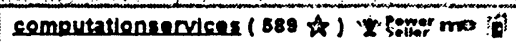

Member aince 07 Jun-04 in Canada

Feedback Score:

Positive Feedback:

Members who let a positive:

Members who left a negative.

All positive Feedback:

का का का का

Eind out mhot these numbers mean

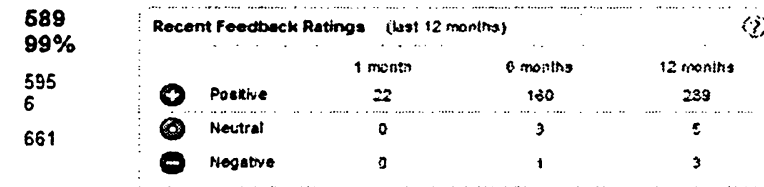

Contactmember Viewitems for salo Vierysellers store More octions -

(6) Dotailed Seller Ratings (ynce kiay 2007)

DThis information will be available when this member receives at least 10 detailed seller ratings.

Foedback as a seller Foedback as a buyer All Feedback Feodback left for others

Ratings mutually withdrawn: 3

687 Foedbeck received

Foudback I Item

(4) Great Ebayer. Fast response and delivery. Great work...... A+++++ Ebayer

Sinuung RORAM RamBu\& $2 \times 25614 B / 16,800.45$ ECC (*220103236684)

il

From / Price

Buyer: morbi soerm ( 37 is) DaterTime 30-Apr-07 05:19 Yiewltem sit $\$ 100 \%$

(eBay Inc.) 


\section{REFERENCE LIST}

British Broadcasting Corporation. Sub-\$100 Laptop Design Unveiled, September 29, 2005, http://news.bbc.co.uk/1/hi/technology/4292854.stm.

Central Intelligence Agency, The World Factbook: United States, https://www.cia.gov/cia/publications/factbook/geos/us.html.

City of Stratford. City Services. http://www.city.stratford.on.ca/site ourcitylife/city services.asp.

City of Toronto. City moves closer to Green Lane Landfill acquisition. http://wx.toronto.ca/inter/it/newsrel.nsf/56025a97a57611d485256dde005a4473/3d39c884 7cd6ecae852572ac0076cc8b?OpenDocument.

Dell Advertisement. 1999. Page B1. The Globe and Mail, January 18.

Dell Inc., Dell Desktops, http://wwwl.ca.dell.com/content/products/category.aspx/desktops?c=ca\&cs=cadhs $1 \& l=e$ n\&s $=$ dhs.

Dell Inc. , Dell Product Recycling, http://support.dell.com/support/topics/global.aspx/support/recycling/en/product recycle.

Diamond, Jared. 2006. Collapse: How Societies Choose to Fail or Succeed (New York: Penguin Books).

eBay Inc. Member Profile: computationservices.

http://feedback.ebay.ca/ws/eBayISAPI.dll?ViewFeedback\&userid=computationservices.

Economist Staff Writer 2006. E-Waste. The Economist, August 25.

Economist Staff Writer 2006. The PC's $25^{\text {th }}$ birthday. The Economist, July 27.

Electronics Product Stewardship Canada, 2006, Guidance Document: Environmentally Sound Recycling of Electronics, Version 2.1. (March)

http://www.epsc.ca/pdfs/March2006_RVQP_GD.pdf.

Elkington, John. 1998. Cannibals with Forks (Gabriola Island: New Society Publishers).

European Commission, Waste Electrical and Electronic Equipment. http://ec.europa.eu/environment/waste/weee/index en.htm.

Forbes.com Inc. Apple Could Grow Global PC Market Share to 5\% in 2005, March 18, 2005, http://www.forbes.com/markets/2005/03/18/0318automarketscan10html. 
Goodman, Peter S. 2004. Booming China Devouring Raw Materials: Producers and Suppliers Struggle to Feed a Voracious Appetite. Washington Post. May 21. http://www.washingtonpost.com/wp-dyn/articles/A43765-2004May20.html.

Greenpeace, Where does e-waste end up?

http://www.greenpeace.org/international/campaigns/toxics/electronics/where-does-ewaste-end-up.

Hewlett-Packard Development Company, L.P., Compaq Desktop PCs. http://www.hp.ca/products/static/presario-desktops/.

Intel Corporation, Moore's Law: Made Real by Intel Innovation. http://www.intel.com/technology/mooreslaw/index.htm.

Jang, Yong-Chul and Timothy G. Townsend. 2003. Leaching of Lead from Computer Printed Wire Boards and Cathode Ray Tubes by Municipal Solid Waste Landfill Leacates. Environmental Science and Technology 37, no. 20:4778-4784.

Kuehr, Ruediger and Eric Williams, eds. 2003. Computers and the Environment: Understanding and Managing their Impacts (Dordrecht: Kluwer Academic Publishers).

LeClaire, Jennifer. 2002. Toshiba Topples Dell in Global Notebook Battle. E-Commerce Times. June 3. http://www.ecommercetimes.com/story/18046.html.

Long, Mark. 2004. The New Computer Lifecycle: No Free Lunch. February 19. http://www.newsfactor.com/story.xhtml?story title=The New_Computer_Lifecycle $\mathrm{N}$ o. Free Lunch\&story id=23205.

Macauley, Molly, Karen Palmer, and Jhih-Shyang Shih. 2003. Dealing with Electronic Waste: Modeling the Costs and Environmental Benefits of Computer Monitor Disposal. Journal of Environmental Management 68:13-22.

McDonough, William and Michael Braungart. 2002. Cradle to Cradle (New York: North Point Press).

Meinhardt Infrastructure \& Environment Group. 2005. Computer and Peripherals Material Project. (Australian Government Department of Environment and Water Resources, June) http://www.environment.gov.au/settlements/publications/waste/electricals/computerreport/material.html.

Metech-Arm. Apple Computer's Electronic Recycling Program. http://www.recycleapc.com/apple/index.asp.

Minister of the Environment to Bas Balkissoon, 20 December 2004. Ministry of the 
Environment.

http://webservices.siriusweblabs.com/dotconnector/files/domain4116/letter122004.pdf.

Ontario Ministry of the Environment, News Release: Province Acts to Keep Electronics from Landfill: Posts Draft Regulation for Comment; Would Require E-waste Recycling. www.ene.gov.on.ca/envision/news/2004/102601.htm.

Osako, Masahiro, Yong-Jin Kim, and Shin-ichi Sakai. 2004. Leaching of Brominated Flame Retardants in Leachate from Landfills in Japan. Chemosphere 57:1571-1579.

Palmer, Paul. 2007. The Death of Recycling. (March) http://www.rachel.org/.

http://pcenc.atspace.com/processors.htm, Cyrillic language web site containing images of Intel CPUs, 2007.

PC World, 1999. The Digital Century: The PC, CNN.com, November 22, http://www.cnn.com/TECH/computing/9911/22/digital.century/index.html.

Puckett, Jim, Leslie Byster, Sarah Westervelt, Richard Gutierrez, Sheila Davis, Asma Hussain, and Madhumitta Dutta. 2002. Exporting Harm: The High-Tech Trashing of Asia. (Basel Action Network and Silicon Valley Toxics Coalition, February) http://www.ban.org/Ewaste/technotrashfinalcomp.pdf.

Renzetti, Steven. 2005. Canadian Agricultural Water Use and Management. http://139.57.161.145/papers/Ag_Water_Chapter.pdf (accessed November 21, 2005; site now discontinued).

Robinson, John, George Francis, Russel Legge, and Sally Lerner. 1990. Defining a sustainable society: values, principles and definitions. Alternatives 17, no. 2:36-46.

Sheppard, Robert. 2006. Rethinking Incineration: How Long Can Toronto Keep Exporting its Trash? CBC.ca, May 17. http://www.cbc.ca/news/background/realitycheck/sheppard/20060317.html.

Thomson, Dixon. 2002. A Practical Introduction and Guide: Tools for Environmental Management (Gabriola Island: New Society Publishers).

United Nations Environment Programme (UNEP). Parties to the Basel Convention. http://www.basel.int/ratif/convention.htm.

Uryu, Tsutomu, Jun Yoshinaga, and Yukio Yanagisawa. 2003. Environmental Fate of Gallium Arsenide Semiconductor Disposal: A Case Study of Mobile Phones. Journal of Industrial Ecology 7, no. 2:103-112. 
U.S. Department of Commerce, 2004, A Nation Online: Entering the Broadband Age. (September) http://www.ntia.doc.gov/reports/anol/NationOnlineBroadband04.htm.

Waste Diversion Ontario. Welcome to WDO. www.wdo.ca.

Williams, Eric. 2003. Environmental Impacts of Microchip and Computer Production (Tokyo: United Nations University). http://www.environmentalfutures.org/Images/williams.PDF.

Worldwatch Institute. State of the World 2007: Our Urban Future. http://www.worldwatch.org/taxonomy/term/467. 